\title{
Parametric analysis of axial wall conduction in a microtube subjected to two classical thermal boundary conditions
}

\author{
NISHANT TIWARI and MANOJ KUMAR MOHARANA* \\ Department of Mechanical Engineering, National Institute of Technology Rourkela, Rourkela 769008, India \\ e-mail: mkmoharana@gmail.com; moharanam@nitrkl.ac.in
}

MS received 25 October 2018; revised 18 May 2019; accepted 24 May 2019; published online 27 June 2019

\begin{abstract}
Heat transfer in laminar flow microtube is numerically explored with an objective of discriminating conjugate heat transfer process experienced in a microtube under two different thermal conditions. Two classical thermal conditions - constant heat flux and constant wall temperature - are imposed separately on the outer surface of a microtube. Wide parametric variations are considered in this study, for the two thermal conditions, albeit the problem under consideration being very classical from both geometry and thermal condition point of view. The parametric variations considered in this work include wall thickness, wall conductivity and coolant flow rate. An expression for Nusselt number in terms of radial (or transverse) and axial conduction number is presented and validated against existing theoretical correlation as well as reported experimental data for both circular and non-circular channels. Dominance of axial conduction over radial (or transverse) conduction is explored and it is found that the effect of wall material on conjugate heat transfer plays an important role. Additionally, it is also observed that with the increase in coolant flow rate, the ratio of radial to axial conduction number increases for both thermal boundary conditions.
\end{abstract}

Keywords. Axial wall conduction; axial conduction number; radial conduction number; conjugate heat transfer; Nusselt number; microchannel.

\section{Introduction}

One of the greatest challenges in thermal engineering is to enhance the local as well as average heat transfer rate while the temperature difference is limited by the practical conditions. Miniaturization of heat transfer devices increases the heat transfer coefficient due to the higher surface area to volume ratio. In recent times, there has been rapid progress in the development of microchannel-based heat exchangers, thanks to developments in micromachining technology [1]. Miniaturization leads to the flow being mostly laminar in nature along micro-ducts. Laminar flow finds many applications in mini/microchannel-based heat sinks and microfluidic energy devices. Therefore, convection forced by laminar flow in ducts is a fundamental problem of great importance in the design of different energy systems such as heat sink, heat exchangers, etc.

For a constant wall heat flux (hereafter referred to as " $q^{\prime \prime}$ ") applied on the outer surface of a circular tube, there exists a difference in wall temperature between two axial locations where temperature is higher towards the outlet. Axial temperature difference in solid wall results in axial back conduction. In a conventional size tube, the thickness of the tube can be negligible compared with the inner

*For correspondence diameter. Hence, the potential for axial conduction is limited by the axial temperature gradient in wall temperature. Secondly, the magnitude of heat conduction is negligible compared with the amount of heat carried away by fluid through convection. Therefore, the phenomenon of axial conduction will not have much influence on overall heat transfer of the system. Unlike conventional tubes, microtubes will have higher or of the same order of wall thickness compared to its inner radius. Therefore, there exists an additional source (of higher solid cross-sectional area) for axial back conduction in a microtube solid wall in addition to the axial temperature gradient.

Maranzana et al [2] defined a dimensionless number called axial conduction number $(M)$ and suggested that effect of axial wall conduction is negligible if $M<0.01$. Later, this number was further modified by Li et al [3] by including temperature difference (between inlet and outlet) in solid $\left(\Delta T_{s}\right)$ and fluid $\left(\Delta T_{f}\right)$ regions. They found that with increase in wall thickness over hydraulic diameter, it leads to higher discrepancy in overall heat transfer. The results also show that for low values of Reynolds number, the wall conduction effect can lead to higher values. Later on, Rahimi and Mehryar [4] showed that ending length is not a function of tube or channel length physically by comparing results to axial conduction number $M$ [2]. Results show that this ending length depends on flow conditions, tube 
geometry and thermal conductivity of wall and the suggested correlation provides better accuracy compared with other numerical results.

Many correlations based on experimental results have been proposed in literature to predict thermal performance of conventional as well as microchannels/microtubes. Stephan and Preußer [5] proposed Nusselt number correlations for both constant wall heat flux and constant wall temperature for the range of $0.7<\operatorname{Pr}<7$ or $\operatorname{Re} \operatorname{PrD} / L<33$.

Peng and Peterson [6] conducted experimental study on single-phase forced convective heat transfer in a rectangular microchannel $\left(D_{h} \sim 0.133-0.367 \mathrm{~mm}\right)$ using water as the working fluid. Based on experimental data, they derived a correlation for laminar convective heat transfer. Choi et al [7] performed experimental study on laminar flow heat transfer in a microtube by varying hydraulic diameter (3-81.2 $\mu \mathrm{m})$, tube length (24-52 mm) and Reynolds number (20-25,000). Liu et al [8] experimentally investigated forced convective heat transfer in quartz microtubes with inner diameter of 242, 315 and $520 \mu \mathrm{m}$ and proposed a correlation for constant wall heat flux. Results obtained from proposed correlation for Nusselt number were found to be in good agreement with the classical laminar correlations at a lower Re.

It can be assumed that correlations based on experimental study proposed in [2-8] already include axial conduction effect. However, these experiment-based correlations are limited for particular test arrangement conducted during the experimental investigation. Lin and Kandlikar [9] performed theoretical analysis and proposed a new correlation for Nusselt number that includes axial wall conduction effect on local wall and fluid temperature. This correlation is compared to various experimental analyses and found to be in good agreement with experimental data. This result also shows that for higher conductivity channel material, or thicker channel walls, effects of axial wall conduction are not negligible. Though the correlation proposed by Lin and Kandlikar [9] is improvised over older correlations, still conduction effect in radial/transverse direction is missing, which is included in the present work. From this discussion it is found that many correlations of Nusselt number with or without axial conduction number were proposed but few of them included temperature gradient in their correlations.

Secondly, correlations proposed in [2-8] also reveal that main affecting parameters that lead to axial wall conduction effect are solid wall thickness to inner radius ratio $\left(\delta_{s f}\right)$, solid wall to coolant liquid conductivity ratio $\left(k_{s f}\right)$ and coolant flow rate $(\mathrm{Re})$. Considering these parameters, Moharana et al [10] performed a numerical study on conjugate heat transfer in a rectangular microchannel and demonstrated that the actual thermal boundary condition experienced at the solid-fluid interface in a square microchannel (engraved on a solid substrate) is different from the applied/imposed thermal condition.
The results indicate that magnitude of heat flux distribution at the solid-fluid interface is more near the inlet region, and hence heat flux distribution decreases neat the outlet. Observing this, Duryodhan et al [11] used an inclined channel instead of flat channels for redistribution of heat flux. They found that axial wall conduction effect weakens in diverging type of microchannels. Similarly, Sahar et al [12] demonstrated effect of hydraulic diameter and channel aspect ratio in a rectangular microchannel. They found that channel aspect ratio does not affect heat transfer coefficient. However, Moharana and Khandekar [13] find that on changing the aspect ratio with different wall materials, the effect of conjugate heat transfer can be observed. This also indicates that the dominance of axial wall conduction increases with high conductive material.

The situation is slightly different in microtubes compared with non-circular channels (square/rectangular), where it is a one-dimensional phenomenon at any axial location. Recently, the effect of axial wall conduction combined with rarefaction and viscous dissipation was observed by Sen and Darici [14]. The result clearly indicates that fluid properties significantly affect heat transfer performance. Considering this, Zhai et al [15] demonstrated effects of axial wall conduction by varying Peclet number $(P e)$, wall to fluid thermal conductivity ratio $\left(k_{s f}\right)$ and solid wall thickness to tube inner radius ratio $\left(\delta_{s f}\right)$. Results indicate that axial wall conduction lowers local $N u_{z}$ along tube length relative to variable parameters under $q^{\prime \prime}$.

Based on this discussion, wall thickness and material conductivity are found to be important parameters that control overall heat transfer process. However, numerous numerical studies related to conjugate heat transfer have been performed in different designs of microchannels. Most of them focused on parameters such as channel cross-section aspect ratio, shapes of microchannel structure, Reynolds number, etc. [16-19]. Very few studies dealing with finding optimum parameters such as channel aspect ratio, material, thickness, etc. are available in existing literature.

Additionally, many numerical/experimental studies do exist in the literature that deal with the study of conjugate heat transfer or axial back conduction in microtube subjected to either constant wall heat flux [20, 21] or constant wall temperature [22-24] on its outer surface. Conjugate heat transfer effect is not limited to microtubes/microchannels only. It is equally applicable to thick-walled conventional size ducts/pipes. Microtubes/microchannels also fall under the thick-walled system. Daric1 et al [25] and Ates et al [26] explored the conjugate heat transfer effect in thick-walled pipes for hydrodynamically and thermally developing laminar flow. Parametric variations considered in these works are wall thickness ratio, wall-to-fluid thermal conductivity ratio, wall-to-fluid thermal diffusivity ratio and Peclet number. It is observed that heat transfer characteristics are strongly dependent on these parameter values. 
The literature presented earlier reveals that conjugate heat transfer situation arises due to the presence of axial temperature gradient. However, the order of this axial temperature gradient is not reported anywhere. Next, existing correlations for Nusselt number hardly explore the axial temperature gradient. Considering this, a mathematical expression for data reduction of average Nusselt number is proposed that fulfils all these criteria. A detailed theoretical and numerical investigation is undertaken by considering the wide parametric variation of factors affecting the thermal performance of microtube subjected to either constant wall temperature (henceforth $T$ ) or constant wall heat flux (henceforth $q^{\prime \prime}$ ) on its outer surface, and a direct comparison is presented for better clarity. The details are elaborated next.

\section{Method and validation}

To expose the effect induced by axial wall conduction on overall heat transfer in a microtube, the outer surface is separately subjected to two different thermal boundary conditions: constant wall heat flux $q^{\prime \prime}$ or constant wall temperature $T$. Schematic presentation of computational domain of microtube is shown in figure 1.

The heat flux within the wall by means of conduction is coupled with convective heat transfer from solid-fluid interface to the fluid. Such tendency of heat transfer is defined as "conjugate heat transfer". Ideally, conduction heat transfer should be radially towards the solid-fluid interface. However, here due to the presence of axial wall conduction, conduction occurs 'bi-directionally' (see figure 1).

Total thermal resistance offered by microtube is given as follows:

$$
\mathrm{R}_{\text {total }}=\mathrm{R}_{\text {cond }, \|}+\mathrm{R}_{\text {cond }, \perp}+\mathrm{R}_{\text {conv }} .
$$

Conduction thermal resistance in axial direction is given as

$$
\mathrm{R}_{\text {cond }, \|}=\mathrm{R}_{\text {total }}-\mathrm{R}_{\text {cond }, \perp}-\mathrm{R}_{\text {conv }} .
$$

Total conductive and convective thermal resistances as defined by Chai et al [27] are given as

$$
\begin{aligned}
\mathrm{R}_{\text {cond }, \perp} & =\frac{\overline{\mathrm{T}}_{\mathrm{a}}-\overline{\mathrm{T}}_{\mathrm{i}}}{\mathrm{Q}}, \quad \mathrm{R}_{\text {conv }}=\frac{\overline{\mathrm{T}}_{\mathrm{i}}-\overline{\mathrm{T}}_{\mathrm{f}}}{\mathrm{Q}}, \\
\mathrm{R}_{\text {total }} & =\frac{\mathrm{T}_{\text {max }}-\mathrm{T}_{\mathrm{in}}}{\mathrm{Q}},
\end{aligned}
$$

where $\overline{\mathrm{T}}_{\mathrm{a}}, \overline{\mathrm{T}}_{\mathrm{i}}$ and $\overline{\mathrm{T}}_{\mathrm{f}}$ are average temperature of the surface at the thermal condition imposed, solid-fluid interface and bulk, respectively. $T_{i n}$ is bulk temperature at inlet, and $T_{\max }$ is maximum temperature within the microchannel/microtube. Using Eq. (3) in Eq. (2) gives

$$
\begin{aligned}
& \mathrm{R}_{\text {cond }, \|}=\frac{\mathrm{T}_{\max }-\mathrm{T}_{\mathrm{in}}}{\mathrm{Q}}-\frac{\overline{\mathrm{T}}_{\mathrm{a}}-\overline{\mathrm{T}}_{\mathrm{i}}}{\mathrm{Q}}-\frac{\overline{\mathrm{T}}_{\mathrm{i}}-\overline{\mathrm{T}}_{\mathrm{f}}}{\mathrm{Q}}, \\
& \mathrm{R}_{\text {cond }, \|}=\frac{\left(\mathrm{T}_{\max }-\mathrm{T}_{\mathrm{in}}\right)-\left(\overline{\mathrm{T}}_{\mathrm{a}}-\frac{\mathrm{T}_{\mathrm{in}}+\mathrm{T}_{\text {out }}}{2}\right)}{\mathrm{Q}} .
\end{aligned}
$$

Equation (5) can also be used to calculate axial conduction resistance by measuring the fluid temperature at channel inlet and outlet, temperature of the surface at which thermal condition is imposed and at the outlet plane of the solid domain. It can be noted that maximum temperature within the solid domain will always occur at the outlet plane. In an experimental study, fluid inlet and outlet temperature can be measured comfortably. From energy balance

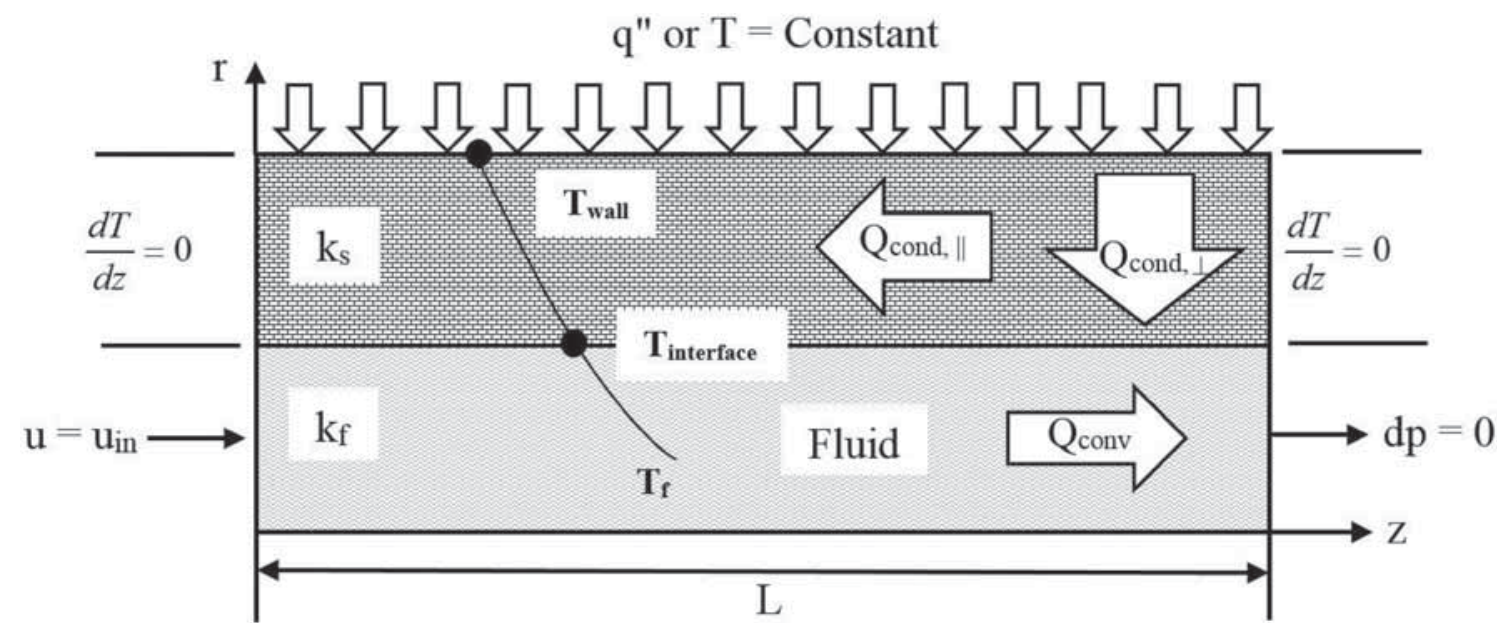

Figure 1. Schematic presentation of computational domain of microtube. 


$$
\mathrm{Q}_{\text {cond }}=\mathrm{Q}_{\mathrm{cond}, \|}+\mathrm{Q}_{\text {cond }, \perp}=\mathrm{Q}_{\mathrm{conv}}
$$

where

$$
\begin{gathered}
Q_{\text {cond }, \perp}=-k_{s} A_{\text {surf }} \frac{d T}{d y}=k_{s} A_{\text {surf }} \frac{\bar{T}_{a}-\bar{T}_{\mathrm{i}}}{\delta_{s}}, \\
Q_{\text {cond }, \|}=k_{s} A_{c s} \frac{T_{w, \text { out }}-T_{w, \text { in }}}{L}, \\
Q_{\text {conv }}=\dot{m} c_{p}\left(T_{b, \text { out }}-T_{b, \text { in }}\right)=\rho A_{c f} U c_{p}\left(T_{b, \text { out }}-T_{b, \text { in }}\right)
\end{gathered}
$$

where $k_{s}, A_{\text {surf }}, A_{c s}, A_{c f}, h$ and $L$ are thermal conductivity of wall material, surface area of solid-fluid interface, crosssectional area of solid wall, cross-sectional area of fluid domain, heat transfer coefficient and length of microchannel/microtube, respectively. Nusselt number with axial wall conduction can be derived from Eqs. (7)-(9):

$$
\begin{gathered}
N u=\frac{\text { Convective heat transfer }}{\text { Conductive heat transfer }} \\
N u=\frac{Q_{\text {conv }}}{\mathrm{Q}_{\text {cond }}}=\frac{Q_{\text {conv }}}{Q_{\text {radial }}+Q_{\text {axial }}}=\frac{1}{\frac{Q_{\text {radial }}}{Q_{\text {conv }}}+\frac{Q_{\text {axial }}}{Q_{\text {conv }}}}=\frac{1}{R+M}
\end{gathered}
$$

where $R$ is radial/transverse conduction number and $M$ is axial conduction number. Using Eqs. (7)-(9) in Eq. (11), we get

$$
\begin{gathered}
N u=\frac{1}{\frac{\left(k_{s} A_{s u f} \frac{\bar{T}_{a}-\bar{T}_{i}}{\delta_{s}}\right)}{\dot{m} c_{p}\left(T_{b, o u t}-T_{b, \text { in }}\right)}-\frac{\left(k_{s} A_{c s} \frac{\left.T_{w, o u t}-T_{w, \text { in }}\right)}{L}\right.}{\dot{m} c_{p}\left(T_{b, \text { out }}-T_{b, \text { in }}\right)}} \\
N u=\frac{1}{k_{s f} \frac{S}{A_{c f}} \frac{\left(\bar{T}_{a}-\bar{T}_{i}\right)}{\left(T_{b, \text { out }}-T_{b, \text { in }}\right)} \frac{D_{h}}{\mathrm{Pe}}-k_{s f} \frac{A_{c s}}{A_{c f}} \frac{\left(T_{w, \text { out }}-T_{w, \text { in }}\right)}{\left(T_{b, \text { out }}-T_{b, \text { in }}\right)} \frac{1}{\mathrm{Pe}} \frac{D_{h}}{L}} .
\end{gathered}
$$

Equation (13) can be used for microchannels of any shape carved on a solid substrate. Here, $S$ is conduction shape factor, which is defined as the ratio of surface area of applied/experienced heat flux to thickness of the wall. Nusselt number for different geometries considered in this work as in table 1 is calculated using Eq. (13), which requires value of $S$, which can be obtained from table 1 .

Table 1. Conduction shape factor for different geometries.

\begin{tabular}{lc}
\hline Geometry & $\begin{array}{c}\text { Conduction shape } \\
\text { factor } S[28]\end{array}$ \\
\hline $\begin{array}{l}\text { Rectangular microchannel with circular } \\
\text { cross-section [29] }\end{array}$ & $S=\frac{2 \pi L}{\ln (0.54 w / r)}$ if $\mathrm{L} \gg \mathrm{w}$ \\
$\begin{array}{l}\text { Wavy microchannel with rectangular } \\
\text { cross-section [30] }\end{array}$ & $S=n \frac{M L_{c}}{N}$ \\
$\begin{array}{l}\text { Straight microchannel } \\
\text { Microtube }\end{array}$ & $S=\frac{2 \pi L}{\ln \left(\frac{\delta_{s}+\delta_{f}}{\delta_{f}}\right)}$ if $\mathrm{L} \gg \delta_{f}$ \\
\hline
\end{tabular}

Graphical method [28] is used for calculation of conduction shape factor $S$ of straight and wavy microchannels where $M$ is number of heat-flow lanes, $N$ is the number of temperature increments between inner and outer surfaces, $n$ is the number of curvilinear-square plots and $L_{c}$ is total curve length of vertical wavy solid-fluid interface, which can be calculated by the least-square method to fit a continuous piecewise linear function.

\subsection{Validation}

Many correlations are available in the literature for predicting average Nusselt number that is developed based on experimental data. The expression for average Nusselt number given in Eq. (13) is validated by direct comparison to selected experimental results reported in the open literature.

2.1a Comparison to experimental data: So far, many experimental studies do exist in the literature related to heat transfer in microchannels and some of them are considered in the present study for validation. For example, Tso and Mahulikar [29] experimentally studied heat transfer in a circular microchannel using water as the coolant. The test section consists of multiple circular microchannels $(d=0.729 \pm 0.027 \mathrm{~mm})$ drilled in an aluminium plate. Experimental data reported in [29] are used in Eq. (13) to calculate average $\mathrm{Nu}$ and are compared to reported experimental average $\mathrm{Nu}$, as shown in figure 2. Figure 2 shows a good agreement between the reported and predicted value of average $\mathrm{Nu}$ using Eq. (13).

Validity of Eq. (13) for the non-circular channel is verified by comparison to experimental data reported in Sui et al [30], which deals with heat transfer in a wavy microchannel with a rectangular cross-section.

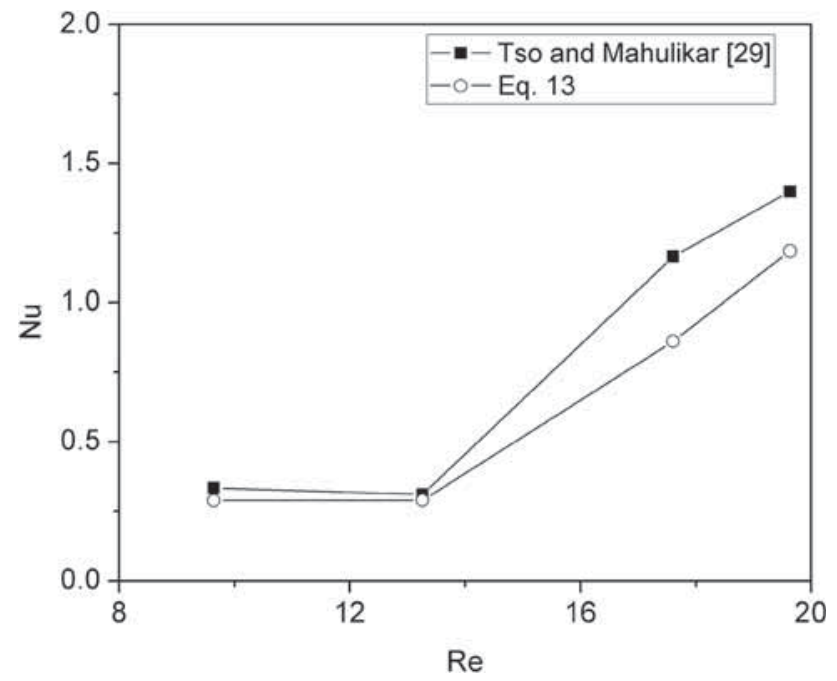

Figure 2. Variation of average $N u$ with $R e$ in a circular microchannel. 
The available data presented by Sui et al [30] are found to be insufficient for predicting average $\mathrm{Nu}$ using Eq. (13). Therefore, to demonstrate the accuracy and reliability of Eq. (13), numerical study has been performed in a copperbased wavy microchannel exactly as considered in [30]. Desired data from this simulation are used in Eq. (13) for predicting average $N u$. Average $N u$ is also calculated completely based on this numerical simulation. The reported experimental test piece $\left(25 \times 25 \times 69.5 \mathrm{~mm}^{3}\right)$ contains 60 parallel wavy (wavelength $2.5 \mathrm{~mm}$, amplitude $259 \mu \mathrm{m}) \quad$ rectangular cross-section microchannels $(205 \mu \mathrm{m} \times 404 \mu \mathrm{m})$ and here we assume that performance of every wavy microchannel is the same. Considering this, we numerically investigated heat transfer performance using water flow in a single wavy microchannel.

Figure 3 presents a comparison between average $\mathrm{Nu}$ obtained from numerical simulation, predicted using Eq. (13), and experimental $N u$ reported by Sui et al [30]. It is clearly depicted in figure 3 that the present numerical result and the prediction using Eq. (13) are in good agreement with the experimental data by Sui et al [30].

$2.1 \mathrm{~b}$ Comparison with existing correlations: Based on an experimental study on laminar flow heat transfer, Stephan and Preußer [5] proposed a correlation for predicting average Nusselt number in circular tube subjected to constant T. Peng and Peterson [6] had proposed a similar correlation for the noncircular channel (subjected to $q^{\prime \prime}$ ) based on their experimental study. The proposed correlation (both for circular and non-circular (see Eq. (13))) is validated against these two correlations and presented in figure 4 for $\operatorname{Pr}=6.99$, where average $\mathrm{Nu}$ varies with Flow Re. The required data for the proposed correlation are obtained from simulation of the exact condition. The proposed correlation is found to be in good agreement to that of Stephan and Preußer [5] and Peng and Peterson [6].

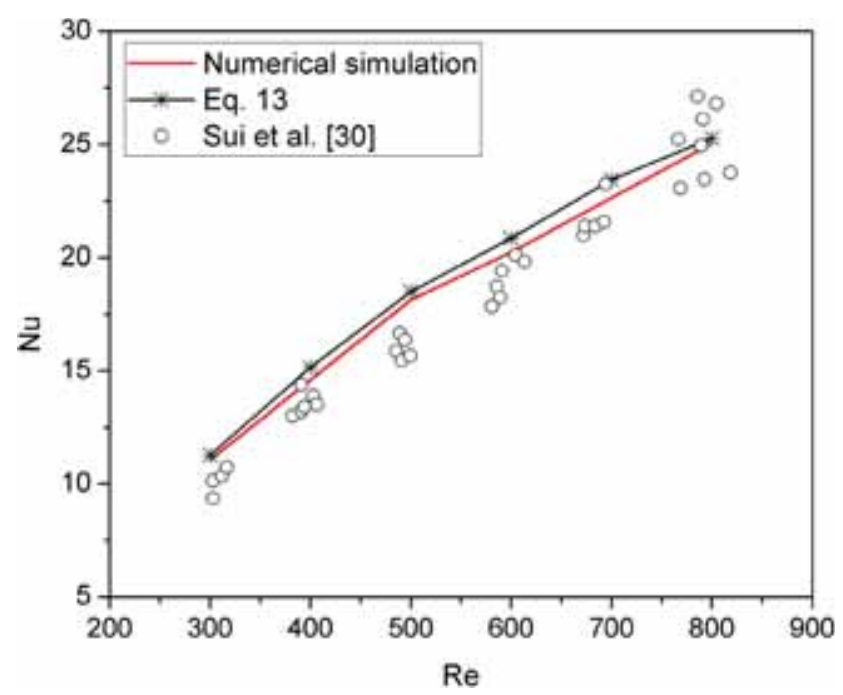

Figure 3. Variation of average $N u$ with $R e$ in a wavy microchannel.

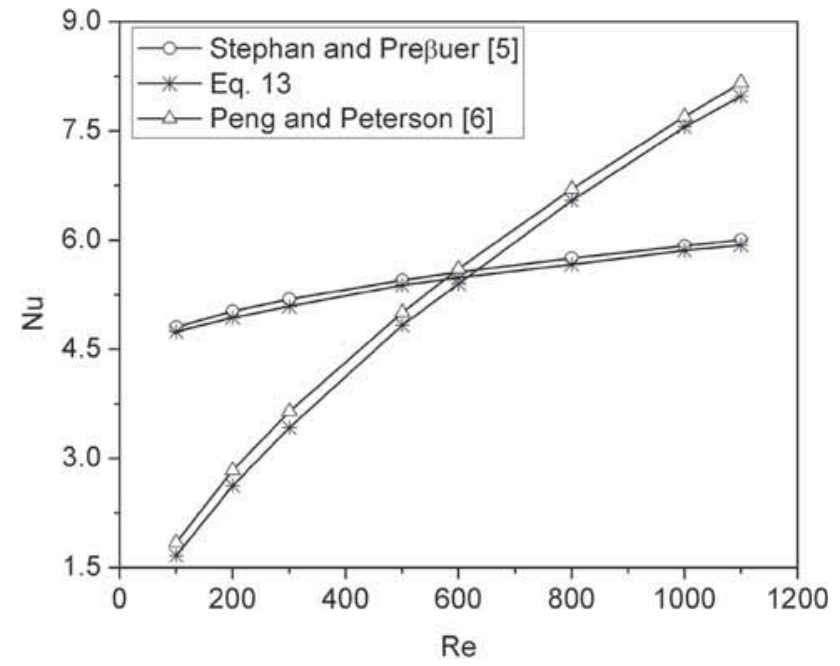

Figure 4. Variation of average $\mathrm{Nu}$ with $\mathrm{Re}$.

Thus, from this validation it can be concluded that the proposed correlation can be used for predicting average $\mathrm{Nu}$ in both circular as well as non-circular microchannels with either $q^{\prime \prime}$ or $T$ boundary conditions. The only limitation of Eq. (13) is that it is dependent on the axial temperature gradient, which is not possible to obtain precisely in any experimental work. However, the advantage of the proposed correlation is that calculation of convective heat transfer coefficient or heat flux at the solid-fluid interface is not required to obtain average $N u$.

Next, to indicate the influence of axial conduction on microtube heat transfer, a detailed numerical investigation is performed and presented. Impact of conjugate heat transfer in terms of axial as well as radial thermal resistance is presented, which has never been explored in the available literature.

\section{Numerical simulation}

Considering angular symmetry, a two-dimensional simulation is carried out for which the computational domain in consideration is presented in figure 1. Unlike conventional circular tubes, the wall thickness of a microtube $\left(\delta_{s}\right)$ is of the order of or higher than its inner radius (represented here as $\delta_{f}$ ). Therefore, while the thickness of the microtube $\left(\delta_{s}\right)$ is varied from 0.2 to $2 \mathrm{~mm}$, the inner radius $\left(\delta_{f}\right)$ and the length of the microtube are maintained at constant values of 0.2 and $60 \mathrm{~mm}$, respectively, such that the solid to fluid thickness ratio $\left(\delta_{s f}=\delta_{s} / \delta_{f}\right)$ varies from 1 to 10 . The outer surface of the microtube is subjected to either $q^{\prime \prime}$ or $T$ separately. The cross-sectional faces of the solid wall are assumed to be adiabatic. Water is used as the coolant, which enters the inlet of the microtube at the ambient temperature of $300 \mathrm{~K}$ where the velocity of water at the inlet is assumed to be constant in the radial direction from 
Table 2. Range of parameters considered in simulations.

\begin{tabular}{lccc}
\hline Flow $R e$ & $k_{s f}$ & $\delta_{s f}$ & $P r$ \\
\hline $100,200,500$ & $2.26-646$ & $1,3,5,10$ & 6.99 \\
\hline
\end{tabular}

the centre of the tube up to the inner radius. The inlet velocity of the fluid is varied such that the flow $R e$ varies from 100 to 500 . The conductivity of the solid wall $\left(k_{s}\right)$ is varied such that the solid to fluid conductivity ratio $\left(k_{s f-}\right.$ $=k_{s}\left(k_{f}\right)$ varies from 2.26 to 646 . The simulations were performed for a wide range of parameters as presented in table 2 .

Secondly, straight and wavy microchannels are also studied, where channel height $\left(\delta_{f}\right)$ and average channel width $\left(\omega_{f}\right.$ or $\left.a\right)$ are kept constant at 0.9 and $0.6 \mathrm{~mm}$, respectively, while amplitude $(A)$ is varied. Thus, with the presence of different expansion factors, performance of a raccoon microchannel is different from that of a wavy microchannel even for both channels having equal waviness. If we compare both microchannels, width $\left(\omega_{f}\right.$ or a) and height $\left(\delta_{f}\right)$ of the straight channel are the same as average width $\left(\omega_{f}\right.$ or $\left.a\right)$ and height $\left(\delta_{f}\right)$ of the wavy microchannel. Thus, the microchannel cross-section is rectangular for all three microchannels. Additionally, to study the conjugate effect on overall heat transfer, substrate thickness $(H)$ of all microchannels is varied from 1.8 to $5.4 \mathrm{~mm}$, while channel height $\left(\delta_{f}\right)$ is kept constant at $0.9 \mathrm{~mm}$. Variation of substrate thickness in dimensionless form is represented by $\delta_{s f}$ (ratio of $\delta_{s}$ to $\delta_{f}$ ) where $\delta_{s}=$ $H-\delta_{f}$ (see figure 5). Thus, the channel aspect ratios $\left(\delta_{f} /\right.$ $\omega_{f}$ ) of straight and wavy microchannels remain constant at 1.5 throughout this study. However, channel aspect ratio varies along the length of the raccoon microchannel except at inlet $(z=0)$ and outlet $(z=L)$, where it is 1.5.

\subsection{Governing equation and boundary condition}

For this purpose, following assumptions are adopted:

1. The flow is steady, laminar and incompressible.

2. The Knudsen number is less than 0.01 , namely the continuum flow regime. Therefore, the microscale thermal and fluidic system cannot take into account the effects of slip flow and temperature jump at the wall.

3. Viscous dissipation in the liquid domain is found to be small enough to be neglected for the range of parameters considered in the present study [22, 31, 32].

4. Constant thermo-physical properties of fluid (variation with temperature is negligible).

5. Heat loss by natural convection or radiation to ambient is neglected.

Thus the 2-D steady Navier-Stokes and energy equations are solved in ANSYS-Fluent ${ }^{\circledR}$ to describe the flow and heat transfer in the whole region. Based on the aforementioned assumptions the problem to be investigated is axisymmetric and the governing equations, i.e. continuity, Navier-Stokes and energy equations, are as follows.

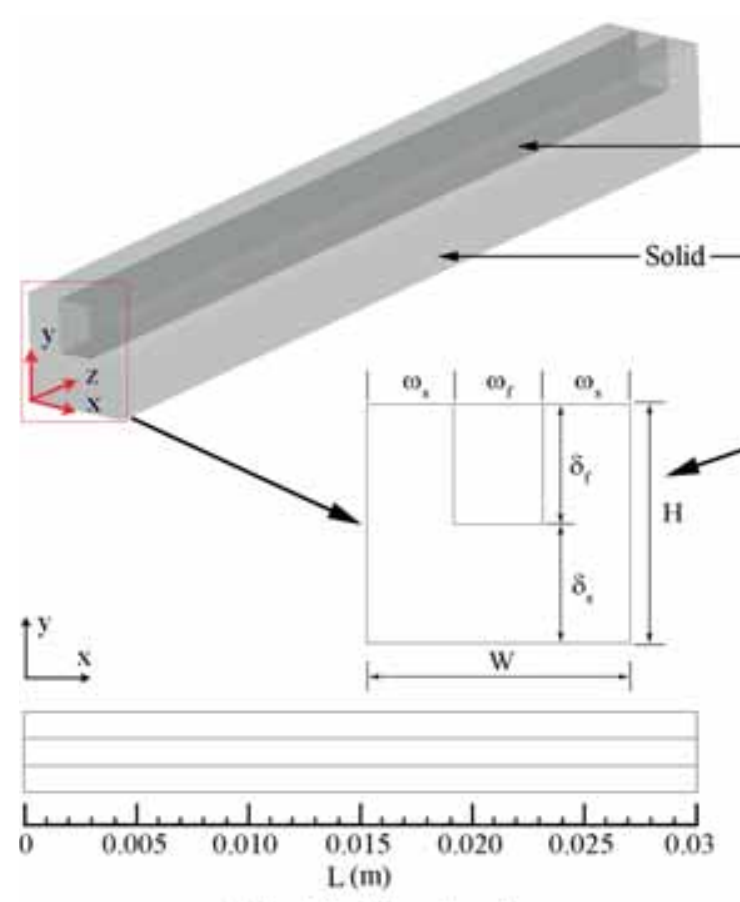

(a) Straight Microchannel

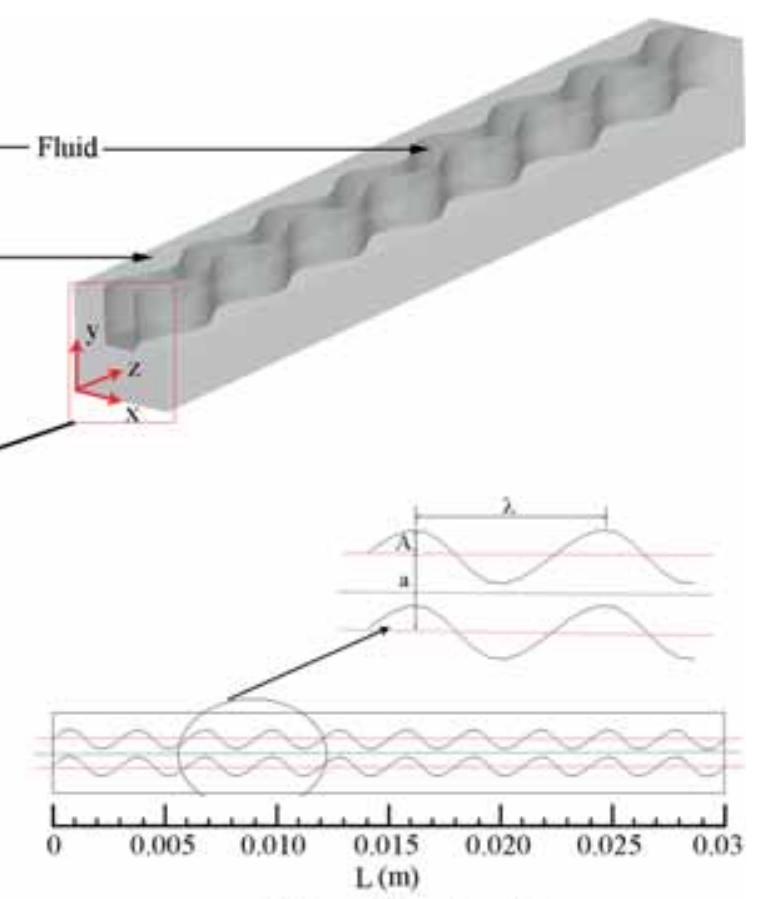

(b) Wavy Microchannel

Figure 5. Schematic diagram of (a) straight microchannel (SMC) and (b) wavy microchannel (WMC). 
For liquid domain:

$$
\begin{gathered}
\nabla \cdot \vec{u}=0, \\
\vec{u} \nabla \vec{u}=-\frac{1}{\rho} \nabla p+\frac{\mu}{\rho} \nabla^{2} \vec{u}, \\
\vec{u} . \nabla T=\left(\frac{k}{\rho C_{p}}\right) \cdot \nabla^{2} T .
\end{gathered}
$$

For solid domain:

$$
\nabla^{2} T=0 .
$$

The associated boundary conditions are as follows:

$$
\frac{\partial \mathrm{T}}{\partial \mathrm{z}}=0 \text { at } \mathrm{z}=0 \text { and } \mathrm{z}=\mathrm{L} \text { and } \delta_{\mathrm{f}} \leq \mathrm{r} \leq\left(\delta_{\mathrm{f}}+\delta_{\mathrm{s}}\right) .
$$

For a fully heated microtube

$$
\begin{gathered}
q^{\prime \prime} \text { or } T=\text { constant at } r=\delta_{s}+\delta_{f}(0 \leq z \leq L), \\
-\mathrm{k}_{\mathrm{s}} \frac{\partial \mathrm{T}}{\partial \mathrm{r}}=\mathrm{h}\left(\mathrm{T}-\mathrm{T}_{\mathrm{f}}\right) \text { at } \mathrm{r}=\delta_{\mathrm{f}}, \\
u=\bar{u} \text { at } z=0, \\
u=0 \text { at } r=\delta_{f}, \\
p=0 \text { at } z=L, \\
\frac{\partial \mathrm{T}}{\partial \mathrm{r}}=0, \frac{\partial \mathrm{u}}{\partial \mathrm{r}}=0 \text { at } \mathrm{r}=0 .
\end{gathered}
$$

A structured rectangular elements mesh is used for discretization and standard grid independence test procedure is adopted to select suitable mesh size for every geometry under consideration. The standard SIMPLE algorithm is employed to solve the governing differential equation of pressure-velocity coupling. A second-order discretization scheme is used for the pressure equation and second-order upwind scheme is used to solve both momentum and energy equations. The residual criteria for continuity, momentum and energy equations are taken to be $10^{-6}, 10^{-6}$ and $10^{-9}$, respectively.

\subsection{Grid independence check}

As multiple microchannel geometries (see figures 1 and 5) are considered in this work, the suitable grid size of each microchannel geometry may be different. For this purpose, extensive grid convergence study is performed for each microchannel geometry to find suitable mesh size for each microchannel geometry. For demonstration, microtubes,

\begin{tabular}{|c|c|c|c|c|c|}
\hline No. & $\begin{array}{c}\text { Grid number } \\
\left(\times 10^{5}\right)\end{array}$ & $N u$ & $e \%$ & $\begin{array}{l}\text { Pressure drop } \\
(\mathrm{Pa})\end{array}$ & $e \%$ \\
\hline \multicolumn{6}{|c|}{ Microtube } \\
\hline 1 & 4.89 & 4.3954 & 1.0446 & 282.412 & 1.4275 \\
\hline 2 & 6.58 & 4.4321 & 0.2184 & 282.997 & 1.2234 \\
\hline 3 & 7.64 & 4.4348 & 0.1576 & 284.312 & 0.7644 \\
\hline 4 & 8.78 & 4.4401 & 0.0383 & 284.912 & 0.5549 \\
\hline 5 & 9.15 & 4.4418 & - & 286.502 & - \\
\hline \multicolumn{6}{|c|}{ Straight microchannel } \\
\hline 1 & 2.56 & 4.1398 & 0.9880 & 236.956 & 1.6964 \\
\hline 2 & 4.31 & 4.1574 & 0.5670 & 237.541 & 1.4539 \\
\hline 3 & 8.02 & 4.1616 & 0.4665 & 238.856 & 0.9085 \\
\hline 4 & 10.48 & 4.1679 & 0.3169 & 239.456 & 0.6595 \\
\hline 5 & 20.70 & 4.1811 & - & 241.046 & - \\
\hline \multicolumn{6}{|c|}{ Wavy microchannel } \\
\hline 1 & 1.29 & 4.9751 & 1.2835 & 336.987 & 1.0658 \\
\hline 2 & 4.33 & 5.0051 & 0.6882 & 337.988 & 0.7721 \\
\hline 3 & 6.22 & 5.0228 & 0.3377 & 339.118 & 0.4403 \\
\hline 4 & 12.15 & 5.0284 & 0.2262 & 339.321 & 0.3807 \\
\hline 5 & 21.60 & 5.0398 & - & 340.618 & - \\
\hline
\end{tabular}
straight and wavy microchannels with wall thickness to channel height/inner radius ratio $\delta_{s f}=1$ are considered and detailed geometrical dimensions of the microchannels are presented in table 3 . The optimum finer mesh is selected to
Table 3. Overall geometric dimensions of the microchannels shown in figure 5.

\begin{tabular}{lccccccc}
\hline Microchannel & $\omega_{s}^{*}$ & $\omega_{f}^{*}$ & $\delta_{c}{ }^{*}$ & $H^{*}$ & $L^{*}$ & $S$ & $\gamma$ \\
\hline Straight & 0.6 & 0.6 & 0.9 & 1.8 & 30 & 1.5 & 0 \\
Wavy & 0.6 & 0.6 & 0.9 & 1.8 & 30 & 1.5 & 0.2 \\
\hline
\end{tabular}

*All dimensions are in $\mathrm{mm}$.

Table 4. Effect of grid size on average Nusselt number and pressure drop.

capture high fluxes (gradients) near solid-fluid interfaces and fluid region.

Table 4 presents different grids considered for straight, wavy and raccoon channels at Reynolds number of 100 . Relative error $(e \%)$ [17] is calculated using

$$
\mathrm{e} \%=\left|\frac{\mathrm{J}_{1}-\mathrm{J}_{2}}{\mathrm{~J}_{1}}\right| \times 100
$$

where $J_{i}(i=1,2)$ represents parameter of interest, i.e. Nusselt number, pressure drop, etc. Here, $J_{1}$ is value of the parameter acquired from the finest grid, whereas $\mathrm{J}_{2}$ represents value of the parameters obtained from other grids.

For attaining higher order accuracy in numerical results, convergence study is carried out and five suitable choices of grid size are made for all geometries and their grid numbers are shown in table 4. For the straight microchannel, it can be observed that local Nusselt number along the channel length is found to vary by $0.98 \%$ and pressure drop varies by less than $1.69 \%$ when shifted from the first grid (no. 1) to last grid (no. 5). Hence, grid no. 4 is selected with 
maximum error percentage within $0.65 \%$ for this study. Similarly, for the other two geometries (wavy and raccoon), grid no. 3 is suitably selected, which is highlighted (bold) in their relevant sections of table 4 , as it reveals the best tradeoff between both accuracy and CPU time.

\subsection{Data reduction}

The axial coordinate $z$ in non-dimensional form is defined as

$$
z^{*}=\frac{z}{L}
$$

The non-dimensional local heat flux at the solid-fluid interface is defined as

$$
\phi=\frac{q_{e}^{\prime \prime}}{q_{i}^{\prime \prime}} .
$$

Here $q_{e}^{\prime \prime}$ is the heat flux value experienced at the solidfluid interface for either $q^{\prime \prime}$ or $T$ condition imposed on the outer surface of the tube, and $q_{i}^{\prime \prime}$ is the ideal/theoretical heat flux expected locally at the solid-fluid interface along the tube length. From energy balance between the outer surface and the interface, $q_{i}^{\prime \prime}=q_{s}^{\prime \prime}\left(1+\delta_{s f}\right)$ where $q_{s}^{\prime \prime}$ is the heat flux on the outer surface of the tube that is (i) applied (constant along the length of the tube) in the case of $q^{\prime \prime}$ condition and (ii) experienced (varying along the length of the tube) in the case of $T$ condition. The dimensionless bulk and wall temperatures are given by

$$
\Theta_{w}=\frac{\left(T_{w}-T_{f i}\right)}{\left(T_{b o}-T_{b i}\right)}, \Theta_{f}=\frac{\left(T_{f}-T_{f i}\right)}{\left(T_{b o}-T_{b i}\right)}
$$

where $T_{b i}$ and $T_{b o}$ are the bulk temperature at the tube inlet and outlet, respectively; $T_{b}$ is the bulk temperature at any axial location and $T_{w}$ is the wall temperature at the same location. Local Nusselt number and local heat transfer coefficient are given by

$$
N u_{z}=\frac{h_{z} \cdot D}{k_{f}}, h_{z}=\frac{q_{i}^{\prime \prime}}{\left(T_{w}-T_{f}\right)},
$$

respectively. The average Nusselt number over total channel length is given by

$$
N u=\frac{1}{L} \int_{0}^{L} N u_{z} d z
$$

\subsection{Validation of numerical results}

The numerical results of local Nusselt number are validated using Lee and Garimella [33] and Perkins et al [34] correlations obtained using water flow in a single microtube of

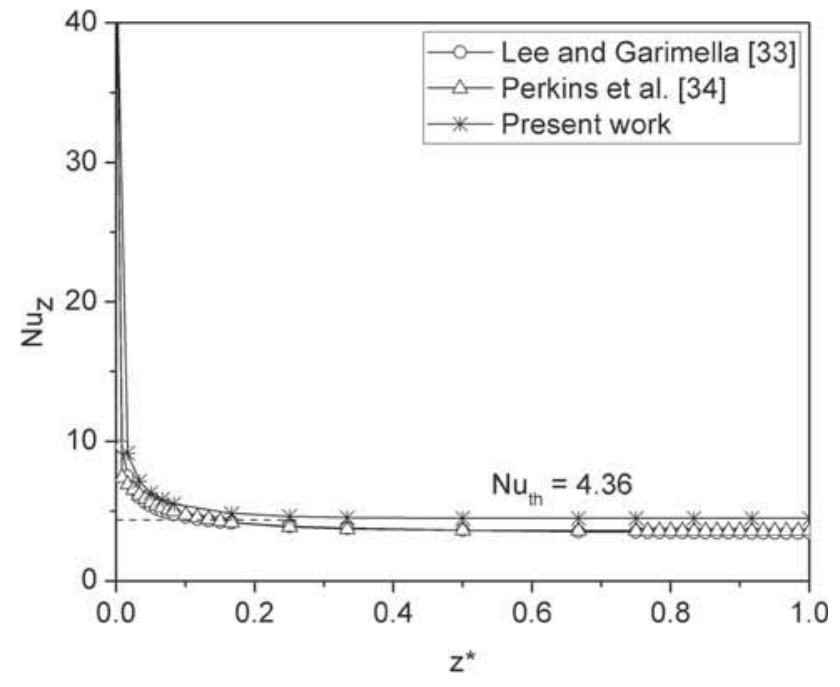

Figure 6. Axial variation of local Nusselt number.

$0.4 \mathrm{~mm}$ diameter and $60 \mathrm{~mm}$ length; $q^{\prime \prime}$ of $45 \mathrm{~kW} / \mathrm{m}^{2}$ is imposed at the outer surface of microtube. It can be seen in figure 6 that numerical predictions are in good agreement with the correlations and theoretical value $\left(N u_{t h}\right)$ in the fully developed region.

\section{Results and discussion}

The parametric variations considered in this study are described in section 3, and also presented in table 2. Overall, the effect of flow $R e$, microtube wall thickness and its material on axial back conduction is explored with the help of axial variation of bulk temperature, heat flux and wall temperature at the solid-fluid interface. The complete study described earlier is carried out distinctly for two separate thermal conditions on the outer surface of the tube: $q^{\prime \prime}$ and $T$.

\subsection{Parametric study of axial wall conduction effect in microtube}

This section highlights parameters that govern heat flow in an axial direction causing axial wall conduction. The parameters included in this study are radial/transverse conduction number $(R)$, axial conduction number $(M)$, axial conductive thermal resistance $\left(R_{\text {cond, } \|}\right)$, convective thermal resistance $\left(R_{\text {conv }}\right)$, tube wall thickness to inner radius ratio $\left(\delta_{s f}\right)$, wall material thermal conductivity $\left(k_{s f}\right)$ and flow $R e$.

The wall thickness of microtube is usually higher than the tube inner radius. In such a scenario, wall thermal resistance becomes an important factor that controls the overall heat transfer process. Considering this, effect of axial conductive thermal resistance $\left(R_{\text {cond,\| }}\right)$ is directly 
Table 5. Axial conduction and convective thermal resistance at different $\delta_{s f}, k_{s f}$ for (a) $R e=100$ and (b) $R e=500$ at $q^{\prime \prime}$.

\begin{tabular}{|c|c|c|c|c|c|c|c|c|c|c|c|}
\hline \multirow[b]{2}{*}{$k_{s f}$} & \multirow[b]{2}{*}{$\delta_{s f}$} & \multirow[b]{2}{*}{$R_{\text {conv }}$} & \multirow[b]{2}{*}{$R_{\text {cond }, \|}$} & \multicolumn{2}{|c|}{ Reduction (\%) } & \multirow[b]{2}{*}{$k_{s f}$} & \multirow[b]{2}{*}{$\delta_{s f}$} & \multirow[b]{2}{*}{$R_{\text {conv }}$} & \multirow[b]{2}{*}{$R_{\text {cond }, \|}$} & \multicolumn{2}{|c|}{ Reduction (\%) } \\
\hline & & & & $R_{\text {conv }}$ & $R_{\text {cond,॥ }}$ & & & & & $R_{\text {conv }}$ & $R_{\text {cond,॥ }}$ \\
\hline \multicolumn{12}{|c|}{ (a) $R e=100, D_{h}=0.4 \mathrm{~mm}, L=60 \mathrm{~mm}, q^{\prime \prime}=88 \mathrm{~kW} / \mathrm{m}^{2}$} \\
\hline 2.26 & 1 & 1.906 & 8.02 & - & - & 2.26 & 5 & 2.64 & 8.98 & - & - \\
\hline 12 & & 1.888 & 8.00 & 0.009 & 0.002 & 12 & & 2.62 & 8.91 & 0.008 & 0.008 \\
\hline 19 & & 1.888 & 8.87 & 0 & -0.109 & 19 & & 2.62 & 7.68 & 0.000 & 0.138 \\
\hline 22 & & 1.888 & 8.86 & 0 & 0.001 & 22 & & 2.62 & 7.27 & 0.000 & 0.053 \\
\hline 60.7 & & 1.890 & 8.82 & -0.001 & 0.005 & 60.7 & & 2.63 & 7.49 & -0.004 & -0.030 \\
\hline 190 & & 1.899 & 8.74 & -0.005 & 0.009 & 190 & & 2.66 & 7.13 & -0.011 & 0.048 \\
\hline 247 & & 1.903 & 8.70 & -0.002 & 0.005 & 247 & & 2.69 & 7.02 & -0.011 & 0.015 \\
\hline 337 & & 1.906 & 8.67 & -0.002 & 0.003 & 337 & & 2.71 & 6.92 & -0.007 & 0.014 \\
\hline 646 & & 1.919 & 8.55 & -0.007 & 0.014 & 646 & & 2.80 & 6.55 & 0.008 & 0.008 \\
\hline 2.26 & 3 & 2.01 & 10.52 & - & - & 2.26 & 10 & 2.42 & 10.45 & - & - \\
\hline 12 & & 1.91 & 10.46 & 0.050 & 0.006 & 12 & & 2.42 & 9.19 & 0.136 & -0.595 \\
\hline 19 & & 1.91 & 10.42 & 0 & 0.004 & 19 & & 2.44 & 9.09 & 0.000 & 0.121 \\
\hline 22 & & 1.91 & 10.41 & 0 & 0.001 & 22 & & 2.44 & 9.06 & -0.008 & 0.011 \\
\hline 60.7 & & 1.99 & 10.26 & -0.042 & 0.014 & 60.7 & & 2.53 & 8.66 & 0.000 & 0.003 \\
\hline 190 & & 1.97 & 9.95 & 0.010 & 0.030 & 190 & & 2.73 & 8.00 & -0.037 & 0.044 \\
\hline 247 & & 2.00 & 9.83 & -0.015 & 0.012 & 247 & & 2.79 & 7.81 & -0.079 & 0.076 \\
\hline 337 & & 2.03 & 9.71 & -0.015 & 0.012 & 337 & & 2.84 & 7.63 & -0.022 & 0.024 \\
\hline 646 & & 2.13 & 9.35 & -0.049 & 0.037 & 646 & & 2.95 & 7.25 & -0.018 & 0.023 \\
\hline \multicolumn{12}{|c|}{ (b) $R e=500, D_{h}=0.4 \mathrm{~mm}, L=60 \mathrm{~mm}, q^{\prime \prime}=88 \mathrm{~kW} / \mathrm{m}^{2}$} \\
\hline 2.26 & 1 & 0.328 & 0.382 & - & - & 2.26 & 5 & 0.437 & 0.376 & - & - \\
\hline 12 & & 0.326 & 0.381 & 0.006 & 0.003 & 12 & & 0.434 & 0.374 & 0.007 & 0.005 \\
\hline 19 & & 0.326 & 0.381 & 0 & 0 & 19 & & 0.434 & 0.372 & 0 & 0.005 \\
\hline 22 & & 0.326 & 0.381 & 0 & 0 & 22 & & 0.434 & 0.372 & 0 & 0 \\
\hline 60.7 & & 0.325 & 0.379 & 0.003 & 0.005 & 60.7 & & 0.434 & 0.364 & 0 & 0.022 \\
\hline 190 & & 0.325 & 0.375 & 0 & 0.011 & 190 & & 0.435 & 0.348 & -0.002 & 0.044 \\
\hline 247 & & 0.325 & 0.374 & 0 & 0.003 & 247 & & 0.435 & 0.341 & 0 & 0.020 \\
\hline 337 & & 0.325 & 0.372 & 0 & 0.005 & 337 & & 0.436 & 0.334 & -0.002 & 0.021 \\
\hline 646 & & 0.326 & 0.367 & -0.003 & 0.013 & 646 & & 0.338 & 0.312 & 0.225 & 0.066 \\
\hline 2.26 & 3 & 0.338 & 0.505 & - & - & 2.26 & 10 & 0.461 & 0.450 & - & - \\
\hline 12 & & 0.328 & 0.504 & 0.030 & 0.002 & 12 & & 0.459 & 0.444 & 0.004 & 0.013 \\
\hline 19 & & 0.327 & 0.502 & 0.003 & 0.004 & 19 & & 0.459 & 0.439 & 0 & 0.011 \\
\hline 22 & & 0.327 & 0.502 & 0 & 0 & 22 & & 0.459 & 0.438 & 0 & 0.002 \\
\hline 60.7 & & 0.326 & 0.496 & 0.003 & 0.012 & 60.7 & & 0.462 & 0.419 & -0.007 & 0.043 \\
\hline 190 & & 0.328 & 0.483 & -0.006 & 0.026 & 190 & & 0.469 & 0.379 & -0.015 & 0.095 \\
\hline 247 & & 0.329 & 0.477 & -0.003 & 0.012 & 247 & & 0.472 & 0.365 & -0.006 & 0.037 \\
\hline 337 & & 0.330 & 0.472 & -0.003 & 0.010 & 337 & & 0.475 & 0.351 & -0.006 & 0.038 \\
\hline 646 & & 0.333 & 0.553 & -0.009 & -0.172 & 646 & & 0.483 & 0.318 & -0.017 & 0.094 \\
\hline
\end{tabular}

compared to a convective thermal resistance $\left(R_{\text {conv }}\right)$ at different $k_{s f}, \delta_{s f}$ and $R e$ for both $q^{\prime \prime}$ and $T$ on the outer surface of microtube and the results are listed in tables 5 and 6 , respectively. Here, convective thermal resistance is inversely proportional to axial conductive thermal resistance. Hence, under ideal thermal condition, lower convective resistance always offers higher axial thermal resistance.

Table 5 presents a comparison between $R_{\text {cond }, \|}$ and $R_{\text {conv }}$ for different $k_{s f}, \delta_{s f}$ and $R e$ for a microtube subjected to $q^{\prime \prime}$. The results show that convective heat transfer in the microtube is lower at high $k_{s f}(\sim 337$ to 646$)$ compared with low $k_{s f}$ values ( $\sim 19$ to 60.7$)$ for all values of $\delta_{s f}$ and $R e$. This happens because a higher temperature gradient is observed at the solid-fluid interface; this allows more heat transfer towards the axial direction, causing low $R_{\text {cond, }, \text {. }}$ Secondly, for $R e=500$, thermal resistance is found to be almost independent of material properties as no significant change is observed with change in $k_{s f}$. Also, convective thermal resistance $\left(R_{\text {conv }}\right)$ increases with increase in $\delta_{s f}$. The negative sign indicates that convective thermal resistance decreases with an increase in immediate higher $k_{s f}$ whereas for axial thermal resistance $\left(R_{\text {cond }, \|}\right)$, the negative sign indicates dominance of axial wall conduction. 
Table 6. Axial conduction and convective thermal resistance at different $\delta_{s f}, k_{s f}$ for (a) $R e=100$ and (b) $R e=500$ at $T$.

\begin{tabular}{|c|c|c|c|c|c|c|c|c|c|c|c|}
\hline \multirow[b]{2}{*}{$k_{s f}$} & \multirow[b]{2}{*}{$\delta_{s f}$} & \multirow[b]{2}{*}{$R_{\text {conv }}$} & \multirow[b]{2}{*}{$R_{\text {cond }, \|}$} & \multicolumn{2}{|c|}{ Reduction (\%) } & \multirow[b]{2}{*}{$k_{s f}$} & \multirow[b]{2}{*}{$\delta_{s f}$} & \multirow[b]{2}{*}{$R_{\text {conv }}$} & \multirow[b]{2}{*}{$R_{\text {cond, }, \|}$} & \multicolumn{2}{|c|}{ Reduction $(\%)$} \\
\hline & & & & $R_{\text {conv }}$ & $R_{\text {cond,॥ }}$ & & & & & $R_{\text {conv }}$ & $R_{\text {cond, },}$ \\
\hline \multicolumn{12}{|c|}{ (a) $R e=100, D_{h}=0.4 \mathrm{~mm}, L=60 \mathrm{~mm}, T=365 \mathrm{~K}$} \\
\hline 2.26 & 1 & 2.173 & 4.050 & - & - & 2.26 & 5 & 1.824 & 3.180 & - & - \\
\hline 12 & & 2.614 & 4.715 & -0.203 & -0.164 & 12 & & 2.517 & 4.455 & -0.380 & -0.401 \\
\hline 19 & & 2.630 & 4.787 & -0.006 & -0.015 & 19 & & 2.575 & 4.616 & -0.023 & -0.036 \\
\hline 22 & & 2.654 & 4.793 & -0.009 & -0.001 & 22 & & 2.584 & 4.645 & -0.003 & -0.006 \\
\hline 60.7 & & 2.649 & 4.816 & 0.002 & -0.005 & 60.7 & & 2.627 & 4.815 & -0.017 & -0.037 \\
\hline 190 & & 2.697 & 4.851 & -0.018 & -0.007 & 190 & & 2.639 & 4.884 & -0.005 & -0.014 \\
\hline 247 & & 2.569 & 4.981 & 0.047 & -0.027 & 247 & & 2.640 & 4.892 & 0 & -0.002 \\
\hline 337 & & 2.442 & 5.111 & 0.049 & -0.026 & 337 & & 2.641 & 4.899 & 0 & -0.001 \\
\hline 646 & & 2.443 & 5.115 & 0 & -0.001 & 646 & & 2.016 & 5.535 & 0.237 & -0.130 \\
\hline 2.26 & 3 & 2.129 & 3.687 & - & - & 2.26 & 10 & 1.521 & 2.923 & - & - \\
\hline 12 & & 2.578 & 4.617 & -0.211 & -0.252 & 12 & & 1.928 & 4.833 & -0.268 & -0.653 \\
\hline 19 & & 2.609 & 4.724 & -0.012 & -0.023 & 19 & & 2.562 & 4.521 & -0.329 & 0.065 \\
\hline 22 & & 2.019 & 5.338 & 0.226 & -0.130 & 22 & & 2.361 & 4.758 & 0.078 & -0.052 \\
\hline 60.7 & & 2.635 & 4.854 & -0.305 & 0.091 & 60.7 & & 2.363 & 4.812 & -0.001 & -0.011 \\
\hline 190 & & 2.641 & 4.897 & -0.002 & -0.009 & 190 & & 2.429 & 5.081 & -0.028 & -0.056 \\
\hline 247 & & 2.642 & 4.902 & 0 & -0.001 & 247 & & 2.430 & 5.091 & 0 & -0.002 \\
\hline 337 & & 2.642 & 4.906 & 0 & -0.001 & 337 & & 2.431 & 5.101 & 0 & -0.002 \\
\hline 646 & & 2.643 & 4.912 & 0 & -0.001 & 646 & & 2.433 & 5.114 & -0.001 & -0.003 \\
\hline \multicolumn{12}{|c|}{ (b) $R e=500, D_{h}=0.4 \mathrm{~mm}, L=60 \mathrm{~mm}, T=365 \mathrm{~K}$} \\
\hline 2.26 & 1 & 0.660 & 0.330 & - & - & 2.26 & 5 & 0.428 & 0.202 & - & - \\
\hline 12 & & 0.916 & 0.459 & -0.388 & -0.391 & 12 & & 0.810 & 0.397 & -0.893 & -0.965 \\
\hline 19 & & 0.836 & 0.681 & 0.087 & -0.484 & 19 & & 0.872 & 0.434 & -0.077 & -0.093 \\
\hline 22 & & 0.932 & 0.497 & -0.115 & 0.270 & 22 & & 0.884 & 0.441 & -0.014 & -0.016 \\
\hline 60.7 & & 0.958 & 0.517 & -0.028 & -0.040 & 60.7 & & 0.951 & 0.484 & -0.076 & -0.098 \\
\hline 190 & & 0.968 & 0.525 & -0.010 & -0.015 & 190 & & 0.977 & 0.503 & -0.027 & -0.039 \\
\hline 247 & & 0.969 & 0.526 & -0.001 & -0.002 & 247 & & 0.979 & 0.505 & -0.002 & -0.004 \\
\hline 337 & & 0.971 & 0.526 & -0.002 & 0.000 & 337 & & 0.982 & 0.507 & -0.003 & -0.004 \\
\hline 646 & & 0.972 & 0.527 & -0.001 & -0.002 & 646 & & 0.986 & 0.510 & -0.004 & -0.006 \\
\hline 2.26 & 3 & 0.555 & 0.264 & - & - & 2.26 & 10 & 0.352 & 0.172 & - & - \\
\hline 12 & & 0.874 & 0.434 & -0.575 & -0.644 & 12 & & 0.767 & 0.370 & -1.179 & -1.151 \\
\hline 19 & & 0.916 & 0.461 & -0.048 & -0.062 & 19 & & 0.845 & 0.413 & -0.102 & -0.116 \\
\hline 22 & & 0.924 & 0.465 & -0.009 & -0.009 & 22 & & 0.781 & 0.491 & 0.076 & -0.189 \\
\hline 60.7 & & 0.966 & 0.494 & -0.045 & -0.062 & 60.7 & & 0.978 & 0.435 & -0.252 & 0.114 \\
\hline 190 & & 0.982 & 0.507 & -0.017 & -0.026 & 190 & & 0.947 & 0.490 & 0.032 & -0.126 \\
\hline 247 & & 0.983 & 0.508 & -0.001 & -0.002 & 247 & & 0.955 & 0.506 & -0.008 & -0.033 \\
\hline 337 & & 0.985 & 0.509 & -0.002 & -0.002 & 337 & & 0.963 & 0.522 & -0.008 & -0.032 \\
\hline 646 & & 0.987 & 0.511 & -0.002 & -0.004 & 646 & & 0.968 & 0.525 & -0.005 & -0.006 \\
\hline
\end{tabular}

For $T$ boundary condition, convective thermal resistance does not make any impact on conduction heat transfer as the outer surface temperature remains unchanged. With the increase in $\delta_{s f}$, the solid-fluid interface moves away from the outer surface. Thus, the decrease in solid-fluid interface temperature with respect to applied condition is limited due to convection to moving fluid. From table 6 , it is clear that with increasing $\delta_{s f}, R_{\text {conv }}$ decreases for all $k_{s f}$. This happens because low conductive material offers higher thermal resistance. Thus, limited fall in temperature at the solidfluid interface is observed. With increasing $k_{s f}$, the fall in interface temperature with respect to applied condition is relatively higher. This induces negative sign in percentage reduction in both $R_{\text {conv }}$ and $R_{\text {cond,\|. }}$.

To explore the insight mechanism of heat transfer within the wall of microtube, radial/transverse conduction number $(R)$ and axial conduction number $(M)$ are computed and their combined effect is presented in figure 7 in terms of the ratio $R / M$. Overall heat conduction through the solid wall consists of both axial as well as radial/transverse conduction between the outer surface and the solid-fluid interface. Theoretically, at constant $N u$, radial conduction number $(R)$ decreases with increasing axial conduction number $(M)$ and vice versa. This is indicated mathematically in 

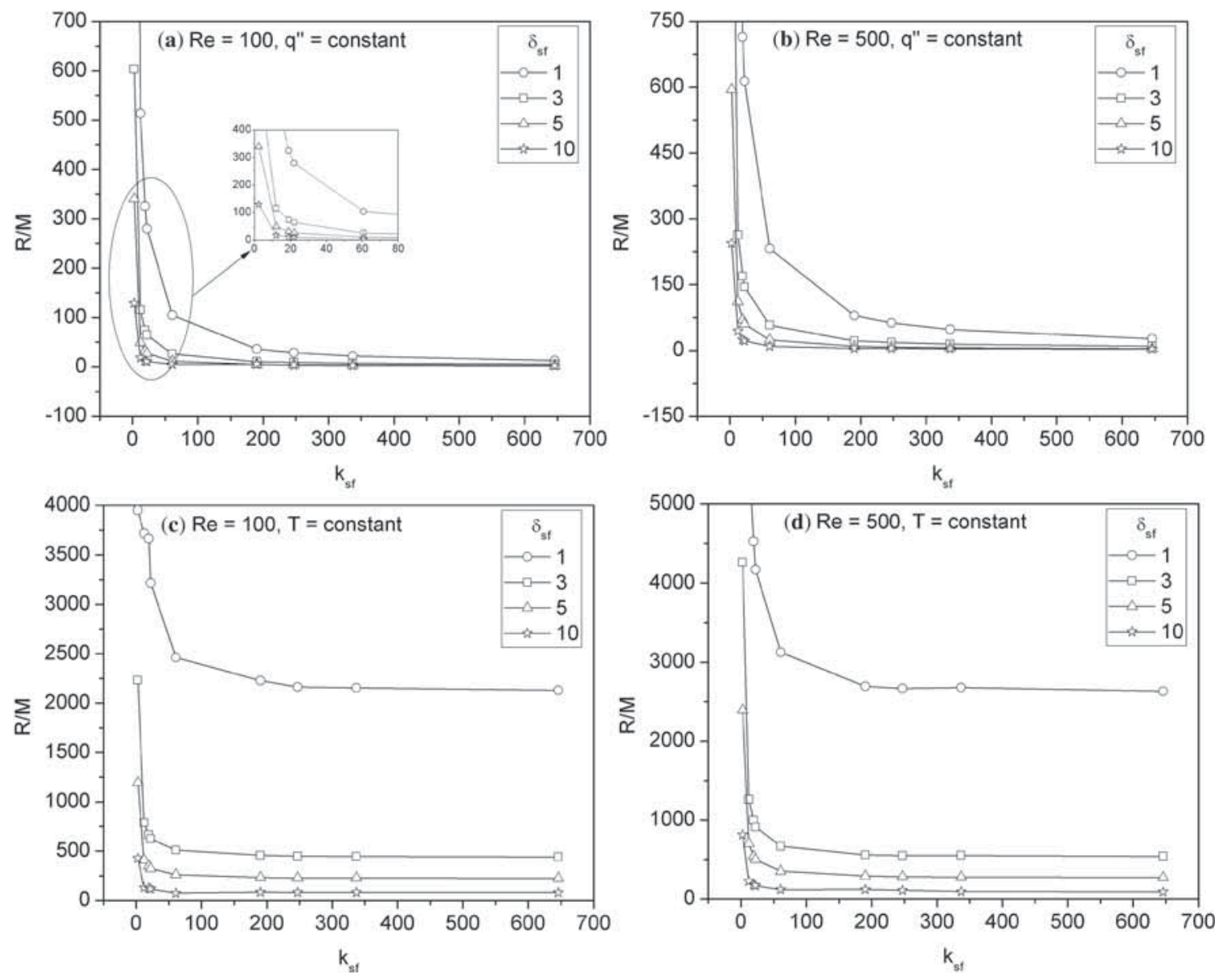

Figure 7. Influence of conduction parameters with varying $k_{s f}$.

Eq. (13). For ideal performance of microtubes it is necessary that axial conduction number $(M)$ should be minimum possible. Figure 7 shows the influence of conduction parameters over a range of $k_{s f}, \delta_{s f}$ and $R e$ for both $q^{\prime \prime}$ and $T$.

It can be observed in figure 7 that at low $k_{s f}$, ratio $R / M$ attains the highest value. This happens because low conductive material $\left(k_{s f}=2.26\right)$ offers higher axial thermal resistance; thus $M$ attains a very small value, which increases the value of $R / M$. As $k_{s f}$ increases, $R / M$ starts decreasing and attains lower values and with further increase in $k_{s f}, R / M$ attains constant value for all $k_{s f}, \delta_{s f}$ and $R e$. This is because a higher conductivity material offers lower thermal resistance, which results in higher temperature gradient (in solid region) between inlet and outlet regions. Thus, it allows more heat conduction in the axial direction, resulting in higher $M$. Additionally, the value of $R$ at any $k_{s f}$ is always found to be greater than that of $M$ for both $q^{\prime \prime}$ and $T$ boundary conditions. Secondly, it can be seen that ratio $R / M$ attains higher value for $T$ boundary condition compared with $q^{\prime \prime}$ boundary condition, which means that with $T$ boundary condition (see figure 7(c) and (d)), $M$ values for all $k_{s f}, \delta_{s f}$ and $R e$ attain lower values compared with $q^{\prime \prime}$ boundary condition (see figure 7(a) and (b)).
Again, it is also observed that with increase in $\delta_{s f}$, the potential of heat flow within the wall in axial direction increases, which results in an increase in the magnitude of $M$ and decrease in the magnitude of $R$ in the same proportion. This indicates the dominance of axial wall conduction. Additionally, the relative difference of $R / M$ increases for $T$ boundary condition compared with $q^{\prime \prime}$ boundary condition. This indicates that with increase in $\delta_{s f}$, dominance of axial wall conduction is found to be higher for $T$ boundary condition compared with $q^{\prime \prime}$ boundary condition. It is also observed that with an increase in $R e$, $R / M$ attains higher values compared with low $R e$ for both $q^{\prime \prime}$ and $T$ boundary conditions. Thus, it can be said that higher $R e$ reduces the dominance of axial wall conduction.

Combined effects of radial conduction number $(R)$ and axial conduction number $(M)$ are presented in figure 8 . The value of $N u$ obtained using Eq. (13) is directly compared with the numerical $\mathrm{Nu}$ average calculated using Eq. (30). To visualize the impact of tube material on overall heat transfer, average Nusselt number predicted for varying $k_{s f}$ (over a broad range) at different flow $R e$ is presented in figure 8(a) and (b) for $q^{\prime \prime}$ and $T$, respectively. The prediction of $\mathrm{Nu}$ using Eq. (13) for different parameters is almost 

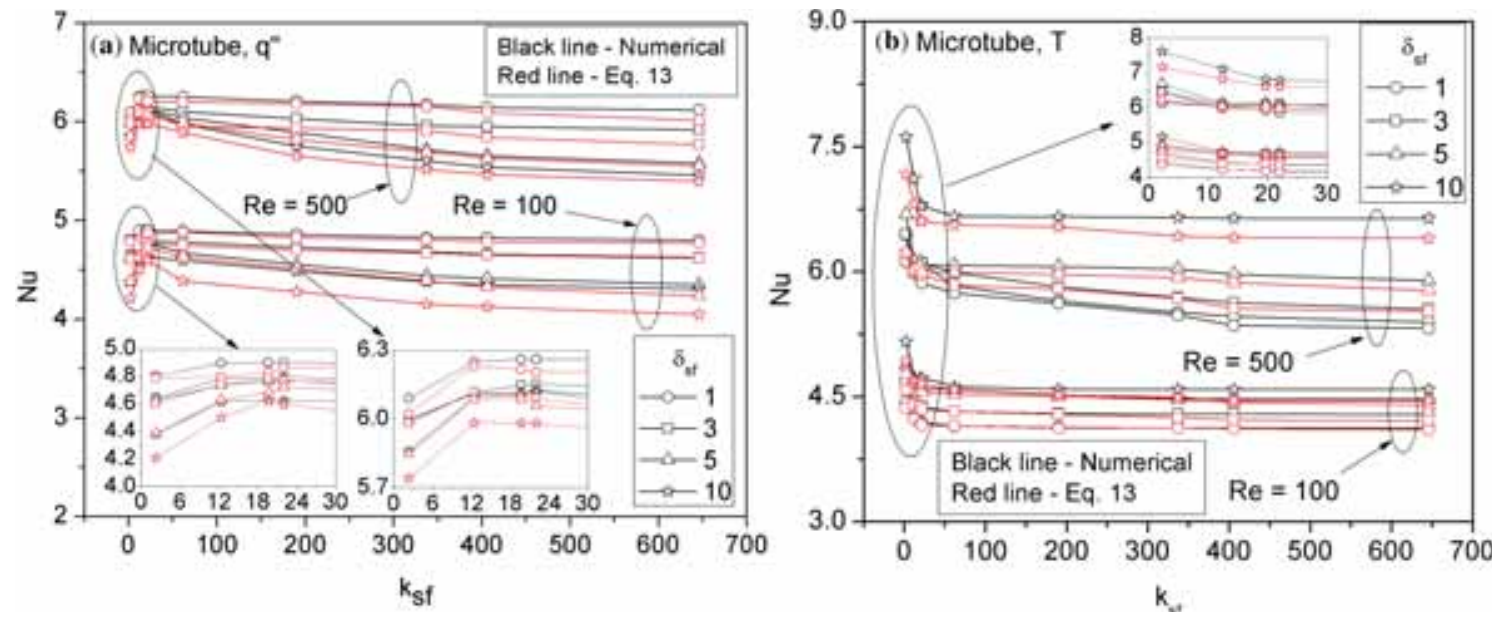

Figure 8. Average Nusselt number varying with $k_{s f}$.

the same as the prediction using Eq. (30), which is based on present numerical simulation. For the case of $q^{\prime \prime}$, the deviation between the two predictions using Eqs. (13) and (30) increases with increasing $\delta_{s f}$, and decreases with increasing $\operatorname{Re}$ (see figure 8(a)). For the case of applied $T$, the deviation between the two predictions using Eqs. (13) and (30) increases with increasing $\delta_{s f}$, and $R e$ (see figure $8(\mathrm{~b})$ ). Maximum deviation is within $6.42 \%$ and $3.62 \%$, respectively, for constant wall heat flux (figure 8(a)) and $T$ (figure 8(b)). Overall it can be concluded that, at higher $\delta_{s f}$, the percentage difference between predicted $N u$ using Eqs. (13) and (30) increases marginally.

The effect of solid conductivity can be seen prominently in figure 8 . For $q^{\prime \prime}$, average $N u$ increases as $k_{s f}$ is decreased from a higher value (see figure 8(a)). However, beyond a threshold value of $k_{s f}$, the average $N u$ starts to decrease with further increase in the value of $k_{s f}$. Thus, there exists an optimum $k_{s f}$ at which average $\mathrm{Nu}$ is maximum. This can be attributed to higher radial thermal resistance compared with axial thermal resistance when $k_{s f}$ value decreases below the threshold value. However, the scenario is different for $T$ as shown in figure $8(\mathrm{~b})$, where average $N u$ attains higher value at low $k_{s f}$ and decreases with increasing $k_{s f}$. Again, beyond a threshold value of $k_{s f}, N u$ remains almost constant or increases by a marginal value for all set of $\delta_{s f}$. However, with increasing tube thickness, thermal resistance in radial direction increases, which results in low $N u$ for all $k_{s f}$ for both thermal boundary conditions.

Again, for any value of $k_{s f}$ and $\delta_{s f}$, the magnitude of average $N u$ increases with increasing flow $R e$. This is due to increase in thermal entry length with increasing flow $R e$. This phenomenon is true for both thermal conditions of $q^{\prime \prime}$ and $T$. Secondly, for $q^{\prime \prime}$, the average $N u$ decreases with increasing wall thickness irrespective of any value of $k_{s f}$, and $R e$, which can be seen in figure 8(a). However, for $T$, average $\mathrm{Nu}$ increases with increasing wall thickness (see figure $8(\mathrm{a})$ ), which is exactly opposite of what happens in case of $q^{\prime \prime}$. This is because higher wall thickness causes higher axial back conduction in solid wall, which leads towards isothermal wall temperature at the solid interface
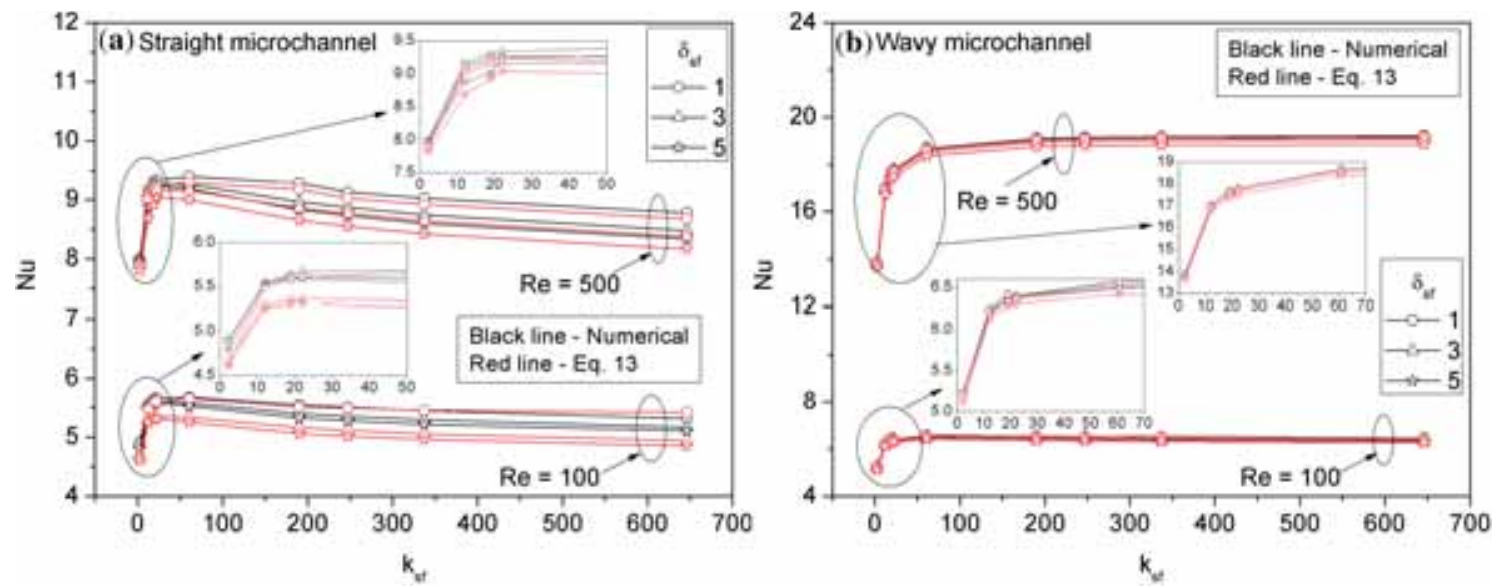

Figure 9. Variation of average $N u$ for straight and wavy microchannels as a function of $k_{s f}$ for $q^{\prime \prime}$. 

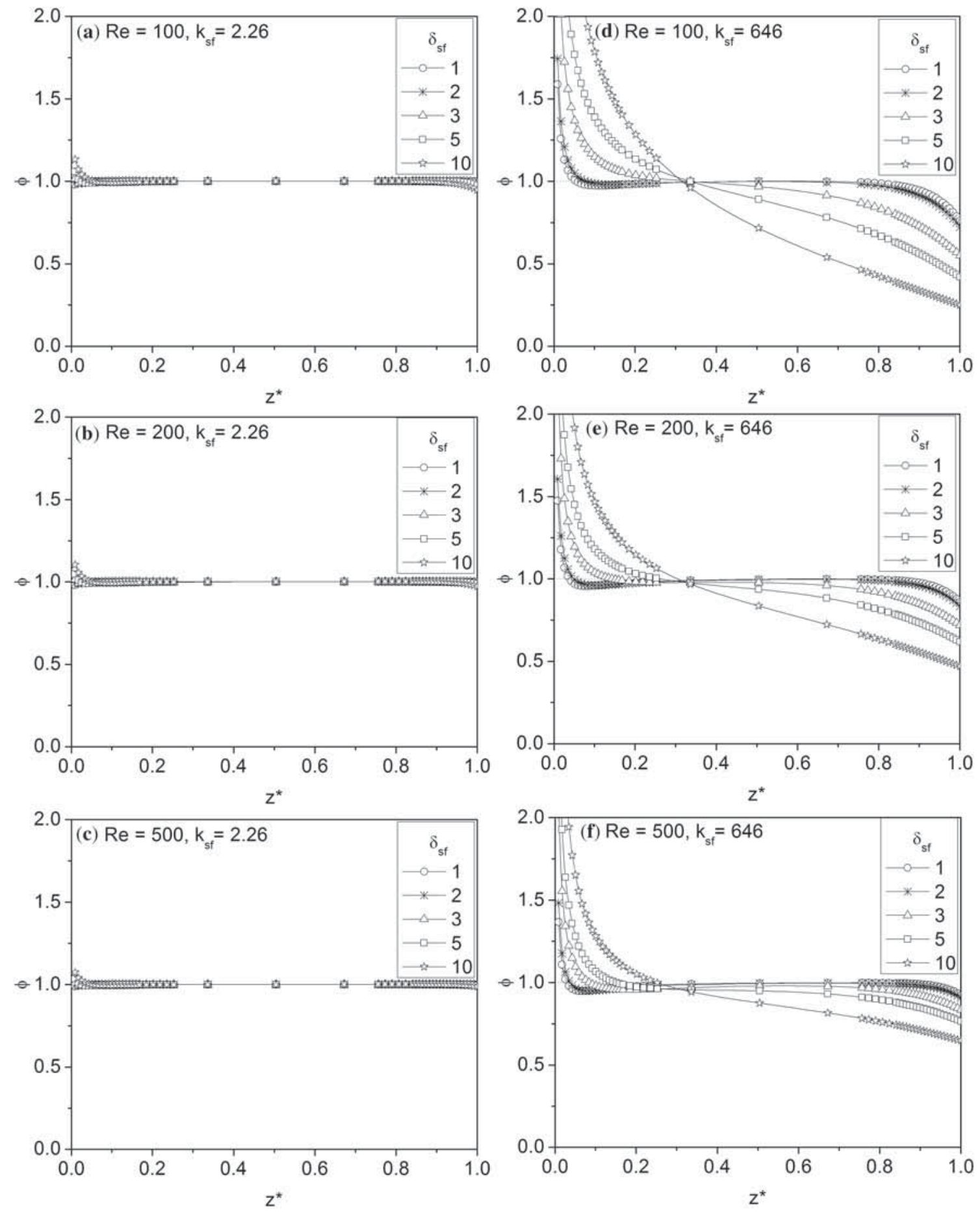

Figure 10. Axial variation of dimensionless local heat flux (at the solid-fluid interface) for $q^{\prime \prime}$.

rather than $q^{\prime \prime}$, though $q^{\prime \prime}$ is applied on the outer surface. Overall, it can be concluded that higher wall thickness decreases overall heat transfer rate when $q^{\prime \prime}$ is applied while it increases overall heat transfer when $T$ is applied.

Similarly, the variation of average $N u$ for straight and wavy microchannels as a function of $k_{s f}$ is presented in figure 9. At low $k_{s f}$, average $N u$ in both straight and wavy microchannels attains lower value for all $\delta_{s f}$ and $R e$. With further increase in $k_{s f}, N u$ increases and attains the highest value for both straight and wavy microchannels at $k_{s f}=22$ and 60.6, respectively. Beyond these values of $k_{s f}$, average $N u$ in straight microchannel starts decreasing with increase in $k_{s f}$ 

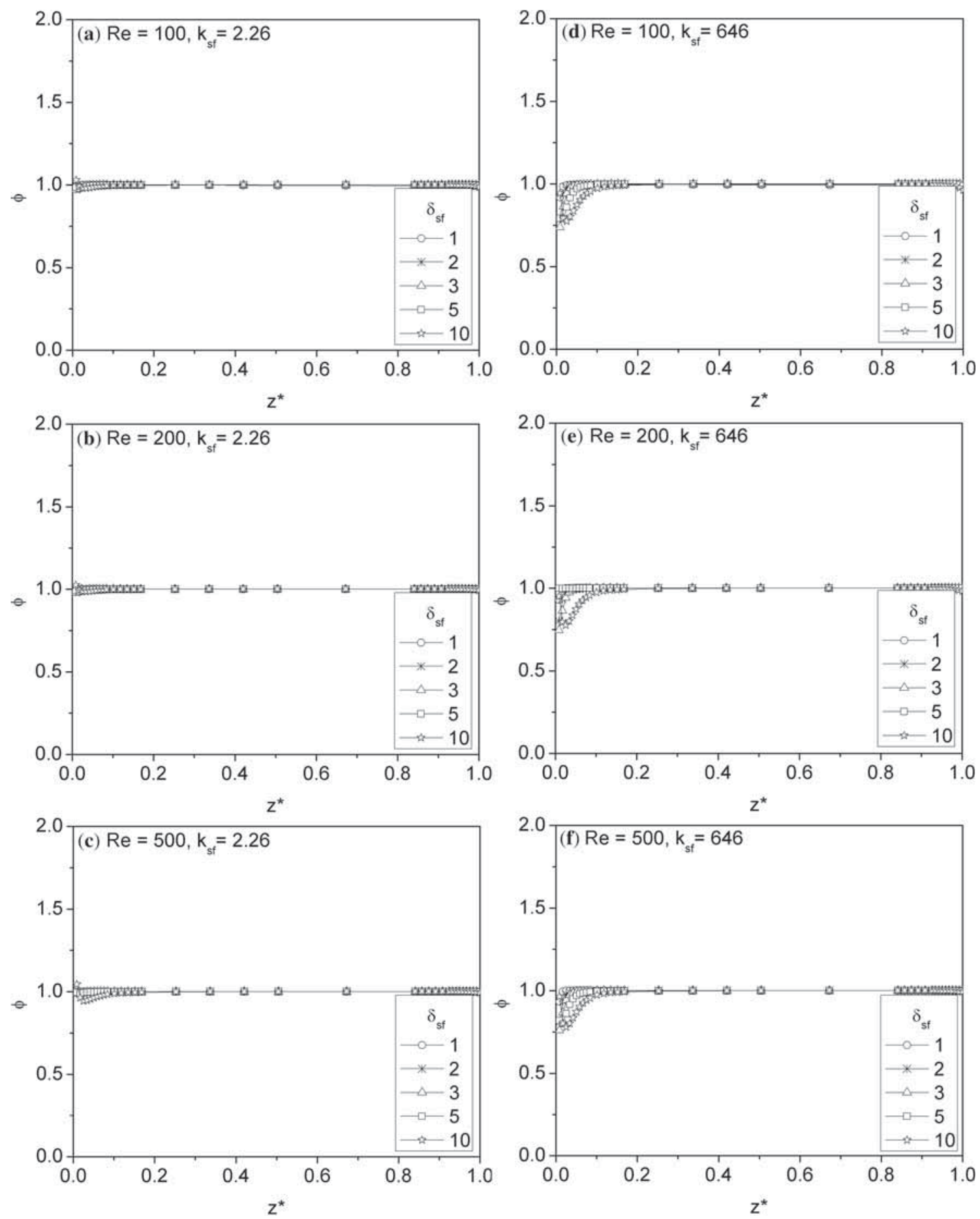

Figure 11. Axial variation of dimensionless local heat flux (at the solid-fluid interface) for $T$.

for all $\delta_{s f}$ and $R e$ while in wavy microchannel it varies negligibly. Additionally, $\mathrm{Nu}$ obtained using Eq. (13) is compared to numerical simulation and it is found that for all $k_{s f}$ there is a good agreement for low $\delta_{s f}$ in straight microchannel and little deviation is observed for higher $\delta_{s f}$ while for wavy microchannel a good match is found for all $k_{s f}, \delta_{s f}$ and $R e$.
From this discussion, it can be recommended that use of wall materials of relatively high conductivity in thickwalled tube or channel (e.g. copper) induces axial wall conduction. Therefore, a material with relatively lower wall conductivity is better in thick-walled tube/channel from the axial wall conduction point of view. 

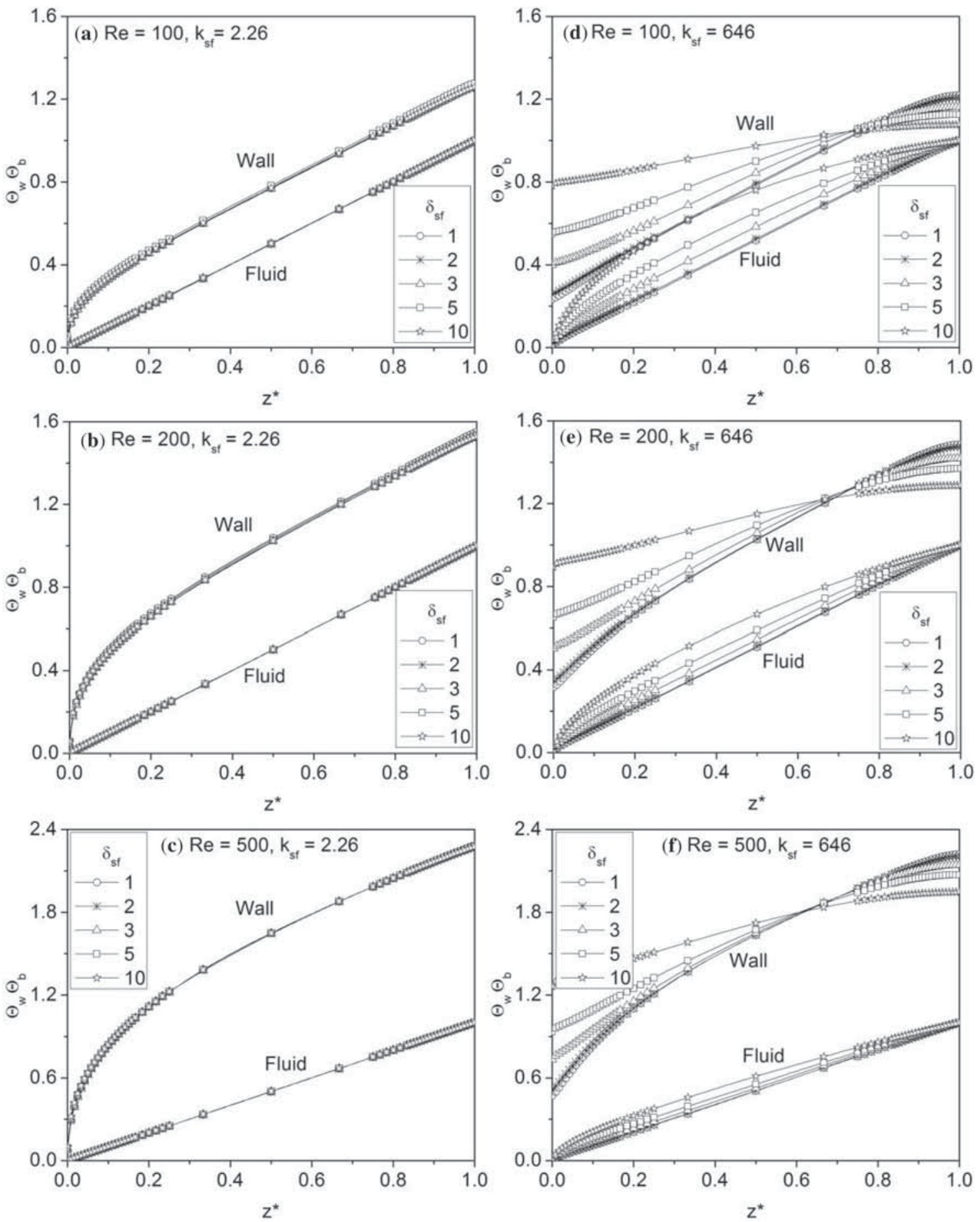

Figure 12. Axial variation of dimensionless wall and bulk temperature for $q^{\prime \prime}$.

\subsection{Effect of wall to fluid conductivity ratio and tube wall thickness to inner radius ratio}

The flux experienced at the solid-fluid interface actually decides the overall heat transfer process as it influences the local wall and fluid temperature, which in turn decides the local heat transfer coefficient and local Nusselt number.
Therefore, the main parameters of interest for this study at the solid-fluid interface are (a) peripheral averaged local heat flux, (b) local bulk temperature and (c) peripheral averaged local wall temperature. Considering angular symmetry (and two-dimensional study to simulate this condition), the values of flux and wall temperature at different axial location points are considered. Similarly, the 

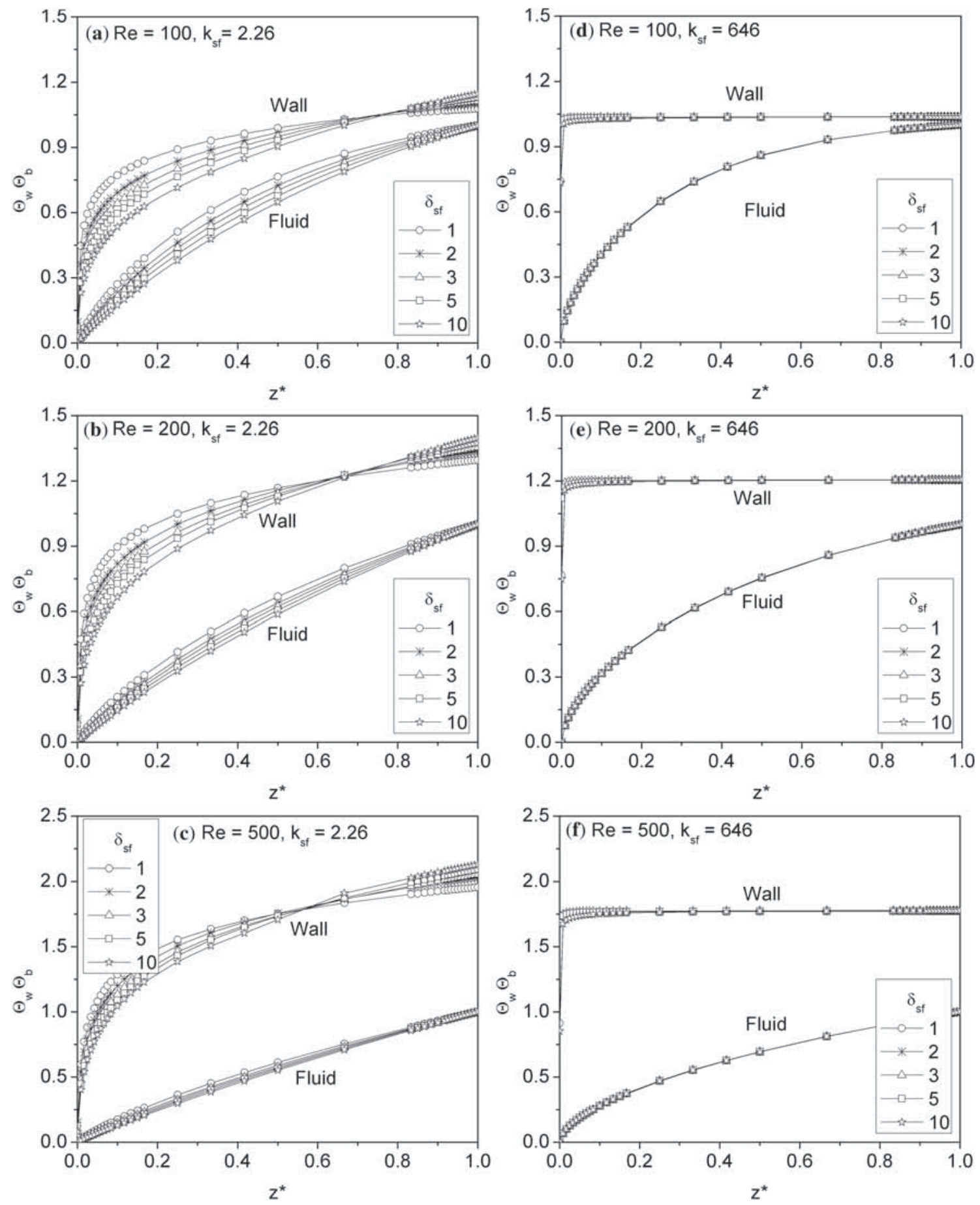

Figure 13. Axial variation of dimensionless wall and bulk temperature for $T$.

bulk temperature is calculated along the radial line. These parameters help us in concluding/predicting the degree to which the axial back conduction in the solid domain influences the local Nusselt number. The conductivity ratio $\left(k_{s f}\right)$ is defined as the ratio of thermal conductivity of the microtube wall material $\left(k_{s}\right)$ to that of the working fluid $\left(k_{f}\right)$.

The axial variation of dimensionless wall heat flux $(\phi)$ is presented in figures 10 and 11 for $q^{\prime \prime}$ and $T$ boundary condition, respectively, at different $R e, k_{s f}$, and $\delta_{s f}$. Among a wide range of $k_{s f}$ values considered in this study, only three representative values of $k_{s f}$, including the extreme lower and higher value ( $k_{s f}=2.26$ and 646), are reported in figures $10,11,12,13,14$ and 15 . As the thickness of the solid wall increases, the heated boundary (outer surface) moves away from the actual solid-fluid interface. Ideally, the dimensionless local heat flux at the solid-fluid interface 

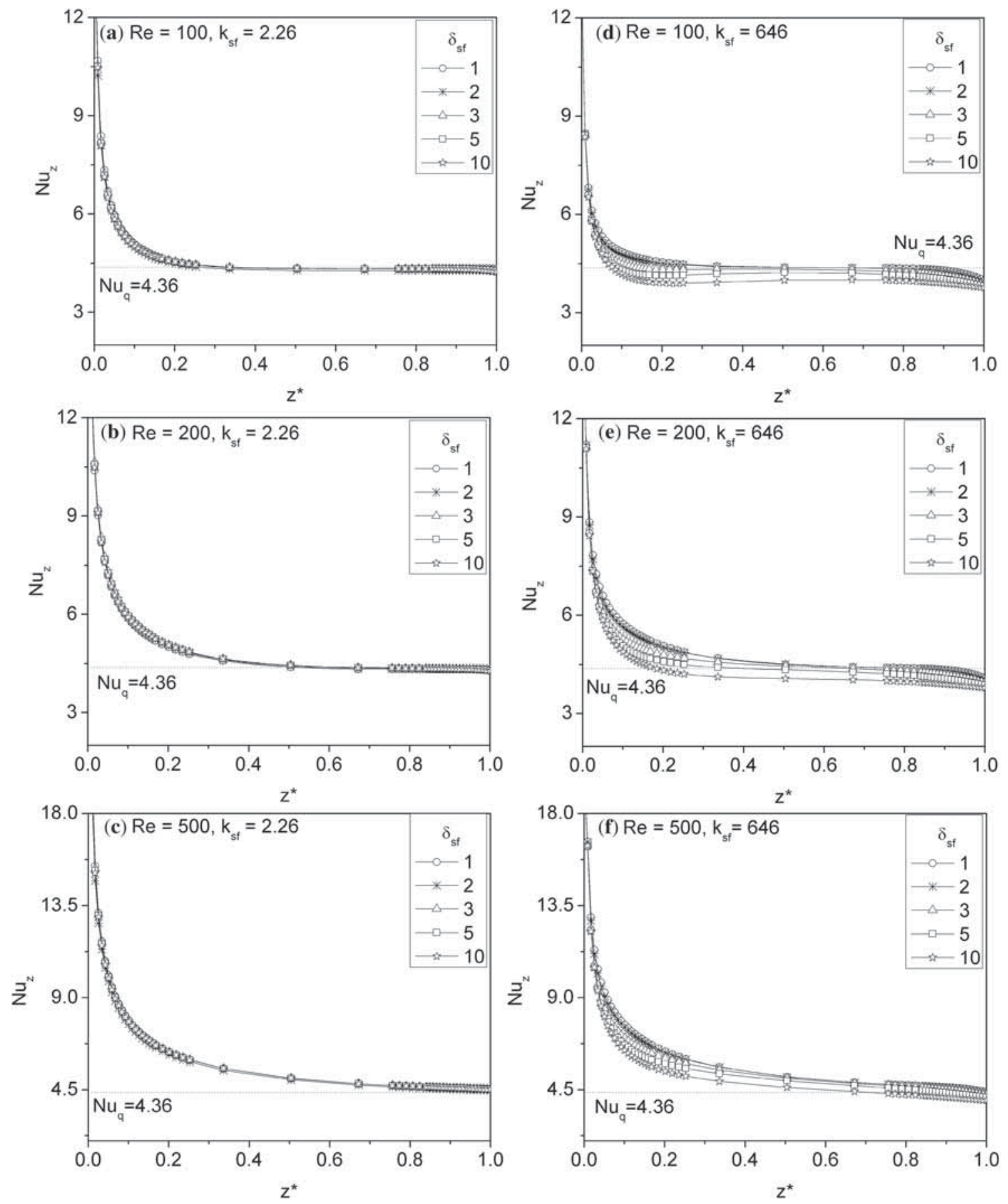

Figure 14. Axial variation of local Nusselt number for $q^{\prime \prime}$.

throughout the length of the microtube should be equal to unity as per the definition used in Eq. (27). This implies that the thermal condition at the solid-fluid interface should have been exactly the same as that imposed on the outer surface of the tube. Any deviation from the ideal value of unity indicates that the thermal condition (either $q^{\prime \prime}$ or $T$ ) at the interface is not the same as that of the corresponding imposed condition on the outer surface. This deviation occurs because of axial flow of heat by conduction in the annular space between the outer surface and the solid-fluid interface, i.e. along the solid wall, called axial wall/back conduction. The direction of this heat flow will be towards the inlet of the microtube.

It can be observed in figure 10(a)-(c) that the dimensionless local heat flux $(\phi)$ at the interface is uniform and equal to unity almost throughout the length irrespective of 

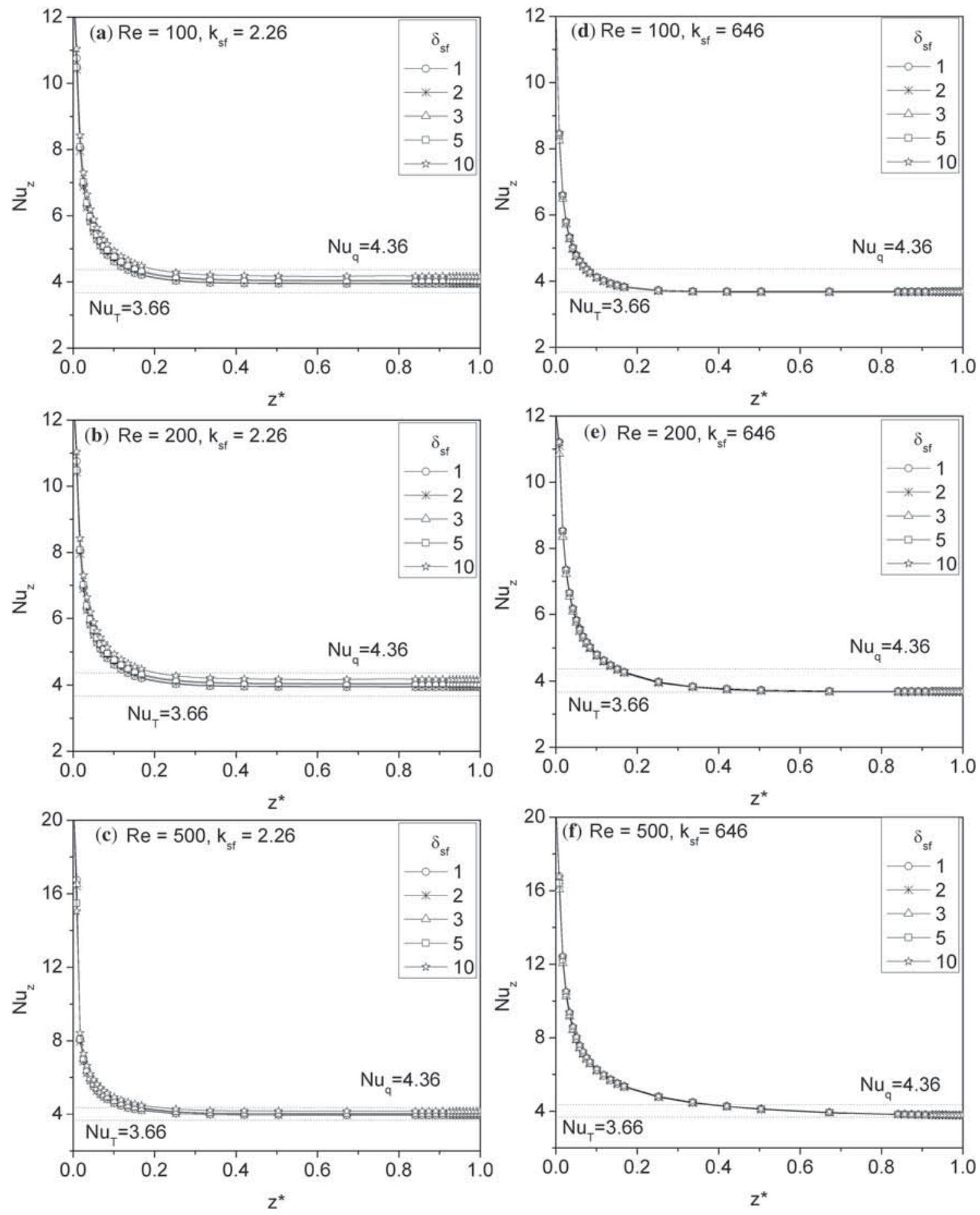

Figure 15. Axial variation of local Nusselt number for $T$.

the value of flow $R e$ and $\delta_{s f}$. This corresponds to $k_{s f}=2.26$, the lowest value among all. The value of $\phi$ corresponding to $k_{s f}=646$ (see figure $10(\mathrm{~d})-(\mathrm{f})$ ) can be found to be completely deviating from the ideal value of unity throughout the length of the microtube. This indicates that with increasing conductivity of the solid (i.e. $k_{s f}$ ), the resistance to axial heat conduction towards the inlet reduces; thus the heat flux near the inlet becomes more than unity, while it becomes less than unity near the outlet. Secondly, it can be observed that for a given solid material (i.e. $k_{s f}$ ) and the relative wall thickness $\left(\delta_{s f}\right)$, the deviation in the value of $\phi$ from its ideal value of unity decreases at any axial location. This can be explained as follows: the higher the flow $R e$, the more the amount of heat transfer by 
convective heat transfer process. Thus, there is less opportunity for conduction of heat due to decrease in the slope of the axial wall temperature. Finally, it can be observed that for a given $k_{s f}$ and $R e$, the deviation in the value of $\phi$ from its ideal value of unity increases with increasing wall thickness $\left(\delta_{s f}\right)$. This is because of decrease in the thermal resistance to axial heat conduction with increasing wall thickness. At this junction it can be concluded that lower $k_{s f}$, and $\delta_{s f}$, and higher $R e$ are favourable to experience ideal heat flux value at the solid-fluid interface when $q^{\prime \prime}$ is imposed on the outer surface of the tube.

Figure 11 presents the equivalent information for a microtube subjected to $T$ condition imposed on its outer surface as in figure 10 for $q^{\prime \prime}$. Ideally, there is no axial temperature gradient. and thus little possibility for axial wall conduction. The basic difference here from that of constant wall heat flux is that some amount of heat flux will be experienced at the outer surface of the microtube, which is used to define the dimensionless heat flux $(\phi)$ as described in section 3.3. Here, it can be observed that there is hardly any effect of $R e, k_{s f}$ and $\delta_{s f}$ except near the inlet.

Figures 12 and 13 show the axial variation of dimensionless wall and bulk temperature as a function of $k_{s f}$, Re and $\delta_{s f}$ corresponding to constant $q^{\prime \prime}$ and $T$ condition, respectively, on the outer surface of the microtube. For $q^{\prime \prime}$ applied on outer surface of the tube, the bulk temperature varies linearly between the inlet and the outlet. As per Eq. (28), the limiting values of $\Theta_{f}$ are 0 and 1, between which the value of $\Theta_{b}$ varies linearly. Again, the difference between the wall and the bulk temperature remains constant in the thermally developed region. This occurs when the wall thickness of the tube is negligible compared with its inner radius. In such case, there is no opportunity for axial back conduction along the solid wall. A similar phenomenon for axial variation of bulk and wall temperature can be found in figure 12(a), which corresponds to lower $k_{s f}$ (=2.26) and $\operatorname{Re}(=100)$. With increasing $R e$, the thermal development length increases, which can be observed in figure 12(b) and (c). Again, with increasing $R e$, the fluid outlet temperature decreases as the same amount of heat is added by applying $q^{\prime \prime}$ on the outer surface of the tube. This makes the difference in fluid outlet and fluid inlet temperatures smaller; thus, the value of wall temperature $\Theta_{w}$ (as defined in Eq. (28)) increases. Secondly, it is important to observe in figure 12(a)-(c) that there is no effect of wall thickness, i.e. $\delta_{s f}$, which is varied from 1 to 10 .

When the $k_{s f}$ value is further increased to 646, a drastic change is observed, which is seen in figure 12(d)-(f). Here, the effect of wall thickness $\delta_{s f}$ starts to dominate. With increase in wall thickness (i.e. $\delta_{s f}$ ), the wall temperature near the inlet increases while it decreases near the outlet; thus, the wall temperature is flattened. This implies that the axial wall conduction distorts the thermal condition experienced at the solid-fluid interface. The thermal condition experienced at the solid-fluid interface is closer to the isothermal wall temperature, rather than the constant wall heat flux applied. This can be supported by the axial variation of bulk temperature, which deviates away from its linearity with increasing $\delta_{s f}$. This deviated axial variation of bulk temperature at higher $\delta_{s f}$ is closer to the bulk temperature of a situation of applied constant $T$.

Next, it can be observed in figure 13(d) that axial wall temperature is isothermal except only near the inlet, which is due to the effect of inlet. Therefore, it can be concluded that the condition experienced at the solid-fluid interface is exactly the same as that applied on the outer surface of the microtube. With increasing flow $R e$, the thermal development length increases, which can be seen in figure 13(e) and (f). Secondly, there is no effect of microtube wall thickness. As the $k_{s f}$ value decreases, the wall temperature deviates from isothermal condition. Also, the bulk temperature approaches towards linearity. Additionally, the wall thickness starts to show its effect, which is more at lower flow $R e$. This can be observed in figure 13(a)-(c).

The combined effect of local heat flux, bulk and wall temperature can be found in the value of Nusselt number, which is defined in Eq. (29), consisting of these three in dimensionless form. The fully developed Nusselt number values are 3.66 and 4.36, respectively, for constant $T$ and $q^{\prime \prime}$ conditions [35]. Fully developed $\mathrm{Nu}$ value is expected to be close to 3.66 corresponding to the situation shown in figure 15(d)-(f). The axial variation of local Nusselt number corresponding to figures 10 and 12 is presented in figure 14, and corresponding to figures 11 and 13 is presented in figure 15 . The values of 3.66 and 4.36 anticipated above based on figures 10,11, 12 and 13 are found to be accurate in the corresponding situation in figures 14 and 15, where the two limiting fully developed $N u$ values are represented by horizontal dashed line.

\section{Summary and conclusion}

Conjugate heat transfer in single-phase laminar developing flow in microtube is studied numerically to find the basic difference in conjugate heat transfer process experienced in a microtube subjected to two different thermal conditions $\left(q^{\prime \prime}\right.$ and $T$ ) imposed on its outer surface. Water at $300 \mathrm{~K}$ enters the microtube and flows through it. The cross-sectional faces of the tube are considered to be adiabatic. The effects of wall thickness, wall material conductivity and flow rate on the axial wall conduction of the microtube are studied. Dimensionless variables considered in this study are (i) solid wall thickness to inner radius ratio $\left(\delta_{s f} \sim 1\right.$ to $10)$, solid wall to working fluid conductivity ratio $\left(k_{s f} \sim 2.2\right.$ to 646) and flow $\operatorname{Re}(100-500)$. An expression for Nusselt number is presented, which includes both radial (or transverse) and axial wall conduction effects. Additionally, conjugate heat transfer effect in the straight and wavy microchannels is also studied and comparison between 
numerical simulation and the generalized expression for Nusselt number is presented.

The outcomes of this study are as follows:

1. An equation (Eq. (13)) is presented for calculating $N u$ of any geometry of microchannel subjected to either $q^{\prime \prime}$ or $T$ boundary condition.

2. The present study reveals that with $R e \geq 500$, the performance of microtube is independent of wall thickness and tube material effect. Thus, axial wall effect can be neglected in such cases.

3. In today's scenario, most of the single-phase laminar flow analysis is performed for the purpose of heat transfer enhancement. Considering this, a variety of complex shape designs (ribs and cavity, twisted microtube, wavy passage, fins, etc.) has been proposed by the various researchers. Keeping the pressure loss in mind, the Reynolds number cannot be increased; thus, in such conditions, axial wall conduction effect cannot be neglected.

4. For $q^{\prime \prime}$ condition, it is found that with increasing conductivity of the microtube wall material, the axial back conduction dominates; thus, it distorts the heat flux at the solid-fluid interface. The axial variation of wall temperature is flattened and it becomes closer to isothermal wall temperature.

5. For $T$ condition, it is found that the behaviours are exactly opposite to those observed in case of constant wall heat flux. Axial wall conduction starts to dominate for low-wall-conductivity material, and the effect of tube thickness gets prominently observed. With increasing flow $R e$, the situation resembles that of $q^{\prime \prime}$ experienced at the solid-fluid interface.

6 . It is found that for $q^{\prime \prime}$, there exists an optimum-wallconductivity material for which the average Nusselt number over the channel length is maximum. However, no such observation is found in case of constant wall heat flux condition, where it is found that the average Nusselt number over the channel length continuously decreases with increasing wall material conductivity.

From this work as well as previous works in this field, it has already been established that conjugate effects influence overall heat transfer, including local wall temperature, bulk temperature and Nusselt number, in both circular and non-circular mini/micro- as well as conventional channel/ ducts. Therefore, it is now high time to include conjugate effects in textbooks on heat transfer/convective heat transfer in the relevant section. This will enable budding researchers in this field not committing any mistakes in experimental/numerical study to devote some time in exploring this phenomenon at a later stage of their research.

\section{List of symbols}

$A_{c f} \quad$ cross-sectional area of fluid domain, $\mathrm{m}^{2}$
$A_{c s}$

$A_{\text {surf }}$

$c_{p}$

D

$h_{z}$

$k_{s}$

$k_{f}$

$k_{s f}$

L

$M$

$N u_{z}$

$N u_{\text {avg }}$

$P$

$\operatorname{Pr}$

$q^{\prime \prime}$

$\mathrm{q}_{\mathrm{i}}^{\prime \prime}$

$\mathrm{q}_{\mathrm{s}}^{\prime \prime}$

$Q_{\text {cond,॥ }}$

$Q_{\text {cond }, \perp}$

$Q_{\text {conv }}$

$q_{w}$

$R$

$R e$

$R_{\text {cond,\| }}$

$R_{\text {cond }, \perp}$

$R_{\text {conv }}$

$R_{\text {total }}$

$r_{i}$

$r_{o}$

$T$

$\bar{T}_{a}$

$\bar{T}_{f}$

$T_{b}$

$\bar{T}_{i}$

$T_{w}$

$T_{w, \text { in }}$

$T_{w, \text { out }}$

$U$

$\bar{U}$

Z

$z^{*}$ cross-sectional area of solid wall, $\mathrm{m}^{2}$

surface area of solid-fluid interface, $\mathrm{m}^{2}$

specific heat of fluid, $\mathrm{J} / \mathrm{kgK}$

inner diameter of microtube, $\mathrm{m}$

local heat transfer coefficient, $\mathrm{W} / \mathrm{m}^{2} \mathrm{~K}$

solid thermal conductivity, $\mathrm{W} / \mathrm{mK}$

fluid thermal conductivity, $\mathrm{W} / \mathrm{mK}$

ratio of $k_{s}$ to $k_{f}$

total length of tube, $m$

conduction number in axial direction

local Nusselt number

average Nusselt number

parameter for axial conduction

Prandtl number

constant wall heat flux, W/m ${ }^{2}$

heat flux experienced at the solid-fluid interface

of the microtube, $\mathrm{W} / \mathrm{m}^{2}$

heat flux applied on the outer surface of the microtube, $\mathrm{W} / \mathrm{m}^{2}$

conduction heat transfer in axial direction, W

conduction heat transfer in radial/transverse

direction, W

convective heat transfer, $\mathrm{W}$

wall heat flux, $\mathrm{W} / \mathrm{m}^{2}$

conduction number in radial/transverse direction

(-)

Reynolds number

conduction thermal resistance in axial direction, $\mathrm{K} / \mathrm{W}$

conduction thermal resistance in radial/transverse direction, $\mathrm{K} / \mathrm{W}$

convective thermal resistance, $\mathrm{K} / \mathrm{W}$

total thermal resistance, $\mathrm{K} / \mathrm{W}$

inner radius of microtube, $\mathrm{m}$

outer radius of microtube, $\mathrm{m}$

constant wall temperature, $\mathrm{K}$

average temperature of the surface when the

thermal condition is imposed, $\mathrm{K}$

average temperature of the bulk, $\mathrm{K}$

bulk temperature, $\mathrm{K}$

average temperature of the solid-fluid interface, $\mathrm{K}$

wall temperature, $\mathrm{K}$

wall temperature at the inlet cross-section, $\mathrm{K}$

wall temperature at the outlet cross-section, $\mathrm{K}$

fluid velocity in the axial direction, $\mathrm{m} / \mathrm{s}$

average fluid velocity at inlet, $\mathrm{m} / \mathrm{s}$

axial coordinate, $\mathrm{m}$

non-dimensional axial coordinate

\section{Greek symbols}

$\delta_{f} \quad$ inner radius of the tube, $\mathrm{m}$

$\delta_{s} \quad$ thickness of the tube wall $\left(r_{o}-r_{i}\right), \mathrm{m}$

$\delta_{s f}$ ratio of $\delta_{s}$ to $\delta_{f}$

$\Phi$ non-dimensional local heat flux 
$\Theta$

non-dimensional temperature

\author{
Subscripts \\ $f$ fluid \\ $i$ inner surface of tube \\ $o$ outer surface of tube \\ $s$ solid \\ $w$ tube outer surface/wall
}

\section{References}

[1] Khandekar S and Moharana M K 2014 Some applications of micromachining in thermal-fluid engineering. In: Jain $\mathrm{V} \mathrm{K}$ (Ed.) Introduction to Micromachining, $2^{\text {nd }}$ ed. New Delhi: Narosa Publishing House

[2] Maranzana G, Perry I and Maillet D 2004 Mini- and microchannels: influence of axial conduction in the walls. Int. J. Heat Mass Transf. 47(17-18): 3993-4004

[3] Li Z, He Y L, Tang G H and Tao W Q 2007 Experimental and numerical studies of liquid flow and heat transfer in microtubes. Int. J. Heat Mass Transf. 50(17-18): 3447-3460

[4] Rahimi M and Mehryar R 2012 Numerical study of axial heat conduction effects on the local Nusselt number at the entrance and ending regions of a circular microchannel. Int. J. Therm. Sci. 59: 87-94

[5] Stephan K and Preußer P 1979 Wärmeübergang und maximale Wärmestromdichte beim Behältersieden binärer und ternärer Flüssigkeitsgemische. Chem. Ing. Tech. 51(1): 37

[6] Peng X F and Peterson G P 1996 Convective heat transfer and flow friction for water flow in microchannel structures. Int. J. Heat Mass Transf. 39(12): 2599-2608

[7] Choi S B, Barron R F and Warrington R Q 1991 Fluid flow and heat transfer in micro-tubes. In: Choi D et al (Eds.) Micro-Mechanical Sensors, Actuators and Systems, Proceedings of ASME DSC 32: 121-128

[8] Liu Z G, Liang S Q and Takei M 2007 Experimental study on forced convective heat transfer characteristics in quartz microtube. Int. J. Therm. Sci. 46(2): 139-148

[9] Lin T Y and Kandlikar S G 2012 A theoretical model for axial heat conduction effects during single-phase flow in microchannels. J. Heat Transf. 134(2): 020902

[10] Moharana M K, Singh P K and Khandekar S 2012 Optimum Nusselt number for simultaneously developing internal flow under conjugate conditions in a square microchannel. J. Heat Transf. 134(7): 071703

[11] Duryodhan V S, Singh S G and Agrawal A 2017 Heat rate distribution in converging and diverging microchannel in presence of conjugate effect. Int. J. Heat Mass Transf. 104: 1022-1033

[12] Sahar A M, Wissink J, Mahmoud M M, Karayiannis T G and Ishak M S A 2017 Effect of hydraulic diameter and aspect ratio on single phase flow and heat transfer in a rectangular microchannel. Appl. Therm. Eng. 115: 793-814

[13] Moharana M K and Khandekar S 2013 Effect of aspect ratio of rectangular microchannels on the axial back conduction in its solid substrate. Int. J. Microscale Nanoscale Therm. Fluid Transport Phenom. 4(3-4): 211-229
[14] Şen S and Darici S 2017 Transient conjugate heat transfer in a circular microchannel involving rarefaction, viscous dissipation and axial conduction effects. Appl. Therm. Eng. 111: $855-862$

[15] Zhai L, Xu G, Quan Y, Song G, Dong B and Wu H 2017 Numerical analysis of the axial heat conduction with variable fluid properties in a forced laminar flow tube. Int. J. Heat Mass Transf. 114: 238-251

[16] Tiwari N and Moharana M K 2019 Numerical study of thermal enhancement in modified raccoon microchannels. Heat. Transf. Res. 50(6): 519-543

[17] Ghani I A, Kamaruzaman N and Sidik N A C 2017 Heat transfer augmentation in a microchannel heat sink with sinusoidal cavities and rectangular ribs. Int. J. Heat Mass Transf. 108: 1969-1981

[18] Sidik N A C, Muhamad M N A W, Japar W M A A and Rasid Z A 2017 An overview of passive techniques for heat transfer augmentation in microchannel heat sink. Int. Commun. Heat Mass Transf. 88: 74-83

[19] Li P, Luo Y, Zhang D and Xie Y 2018 Flow and heat transfer characteristics and optimization study on the water-cooled microchannel heat sinks with dimple and pin-fin. Int. J. Heat Mass Transf. 119: 152-162

[20] Avcı M, Aydin O and Arıcı M E 2012 Conjugate heat transfer with viscous dissipation in a microtube. Int. J. Heat Mass Transf. 55(19-20): 5302-5308

[21] Celata G P, Cumo M, Marconi V, McPhail S J and Zummo G 2006 Microtube liquid single-phase heat transfer in laminar flow. Int. J. Heat Mass Transf. 49(19-20): 3538-3546

[22] Koo J and Kleinstreuer C 2004 Viscous dissipation effects in microtubes and microchannels. Int. J. Heat Mass Transf. 47: 3159-3169

[23] Lelea D, Nishio S and Takano K 2004 The experimental research on microtube heat transfer and fluid flow of distilled water. Int. J. Heat Mass Transf. 47(12-13): 2817-2830

[24] Zhang S X, He Y L, Lauriat G and Tao W Q 2010 Numerical studies of simultaneously developing laminar flow and heat transfer in microtubes with thick wall and constant outside wall temperature. Int. J. Heat Mass Transf. 53(19-20): 3977-3989

[25] Darıcı S, Bilir Ş and Ateş A 2015 Transient conjugated heat transfer for simultaneously developing laminar flow in thick walled pipes and minipipes. Int. J. Heat Mass Transf. 84: 1040-1048

[26] Ateş A, Darıcı S and Bilir Ş 2010 Unsteady conjugated heat transfer in thick walled pipes involving two-dimensional wall and axial fluid conduction with uniform heat flux boundary condition. Int. J. Heat Mass Transf. 53(23-24): 5058-5064

[27] Chai L, Xia G, Wang L, Zhou M and Cui Z 2013 Heat transfer enhancement in microchannel heat sinks with periodic expansion-constriction cross-sections. Int. J. Heat Mass Transf. 62: 741-751

[28] Holman J P 1972 Heat transfer, 10 ${ }^{\text {th }}$ ed. New York: McGraw-Hill

[29] Tso C P and Mahulikar S P 2000 Experimental verification of the role of Brinkman number in microchannels using local parameters. Int. J. Heat Mass Transf. 43(10): 1837-1849

[30] Sui Y, Lee P S and Teo C J 2011 An experimental study of flow friction and heat transfer in wavy microchannels with rectangular cross section. Int. J. Therm. Sci. 50: 2473-2482 
[31] Xu B, Ooi K T, Mavriplis C and Zaghloul M E 2003 Evaluation of viscous dissipation in liquid flow in microchannels. J. Micromech. Microeng. 13(1): 53-57

[32] Morini G L and Spiga M 2007 The role of the viscous dissipation in heated microchannels. J. Heat Transf. 129(3): 308-318

[33] Lee P S and Garimella S V 2006 Thermally developing flow and heat transfer in rectangular microchannels of different aspect ratios. Int. J. Heat Mass Transf. 49(17-18): 3060-3067

[34] Perkins K R, Schade K W and McEligot D M 1973 Heated laminarizing gas flow in a square duct. Int. J. Heat Mass Transf. 16(5): 897-916

[35] Bergman T L, Lavine A S, Incropera F P and DeWitt D P 2011 Fundamentals of heat and mass transfer, 7th ed. New York: John Wiley and Sons 